\title{
Transcriptome dynamics and molecular cross-talk between bovine oocyte and its companion cumulus cells
}

\author{
A Regassa, F Rings, M Hoelker, U Cinar, E Tholen, C Looft, K Schellander, D Tesfaye*
}

\begin{abstract}
Background: The bi-directional communication between the oocyte and its companion cumulus cells (CCs) is crucial for development and functions of both cell types. Transcripts that are exclusively expressed either in oocytes or CCs and molecular mechanisms affected due to removal of the communication axis between the two cell types is not investigated at a larger scale. The main objectives of this study were: 1. To identify transcripts exclusively expressed either in oocyte or CCs and 2. To identify those which are differentially expressed when the oocyte is cultured with or without its companion CCs and vice versa.

Results: We analyzed transcriptome profile of different oocyte and CC samples using Affymetrix GeneChip Bovine Genome array containing 23000 transcripts. Out of 13162 genes detected in germinal vesicle (GV) oocytes and their companion CCs, 1516 and 2727 are exclusively expressed in oocytes and CCs, respectively, while 8919 are expressed in both. Similarly, of 13602 genes detected in metaphase II (MII) oocytes and CCs, 1423 and 3100 are exclusively expressed in oocytes and CCs, respectively, while 9079 are expressed in both. A total of 265 transcripts are differentially expressed between oocytes cultured with (OO + CCs) and without (OO- CCs) CCs, of which 217 and 48 are over expressed in the former and the later groups, respectively. Similarly, 566 transcripts are differentially expressed when CCs mature with (CCs + OO) or without (CCs - OO) their enclosed oocytes. Of these, 320 and 246 are over expressed in CCS + OO and CCS - OO, respectively.

While oocyte specific transcripts include those involved in transcription (IRF6, POU5F1, MYF5, MED18), translation (EIF2AK1, EIF4ENIF1) and CCS specific ones include those involved in carbohydrate metabolism (HYAL1, PFKL, PYGL, MPI), protein metabolic processes (IHH, APOA1, PLOD1), steroid biosynthetic process (APOA1, CYP11A1, HSD3B1, HSD3B7). Similarly, while transcripts over expressed in $\mathrm{OO}+\mathrm{CCS}$ are involved in carbohydrate metabolism (ACO1, 2), molecular transport (GAPDH, GFPT1) and nucleic acid metabolism (CBS, NOS2), those over expressed in CCs + $\mathrm{OO}$ are involved in cellular growth and proliferation (FOS, GADD45A), cell cycle (HAS2, VEGFA), cellular development (AMD1, AURKA, DPP4) and gene expression (FOSB, TGFB2).
\end{abstract}

Conclusion: In conclusion, this study has generated large scale gene expression data from different oocyte and CCs samples that would provide insights into gene functions and interactions within and across different pathways that are involved in the maturation of bovine oocytes. Moreover, the presence or absence of oocyte and CC factors during bovine oocyte maturation can have a profound effect on transcript abundance of each cell types, thereby showing the prevailing molecular cross-talk between oocytes and their corresponding CCs.

\footnotetext{
* Correspondence: tesfaye@itw.uni-bonn.de

Institute of Animal Science, Animal Breeding and Husbandry Group,

University of Bonn, Germany
} 


\section{Background}

The bi-directional communications between the oocyte and its companion cumulus cells (CCs) is crucial for the development and functions of both cell types [1-3]. This dialogue is vital for the oocyte to acquire meiotic and developmental competence and for proliferation and differentiation of CCs [1,3-9]. The oocyte regulates proliferation [2,10-13], apoptosis [14], luteinization [13,15], metabolism [16] and expansion $[17,18]$ of CCs through oocyte secreted factors (OSFs) such as growth and differentiation factor 9 (GDF9), bone morphogenetic protein 15 (BMP15) and possibly others. Competent oocytes also influence the expression of cumulus specific biochemical markers that might be crucial for cumulus expansion and thereby achieve maturation and successful development [17-19]. CCs play an important role in the utilization of energy substrates by oocyte [20], prevent the oocyte from oxidative stress induced apoptosis $[21,22]$ and stimulate glutathione synthesis [23,24] during in vitro maturation. The ability of the oocyte to form male pronuclei after fertilization strongly depends on the presence of CCs during maturation [25-27] and fertilization [28-30]. Fertilization and development to a healthy blastocyst is limited by the oocyte quality [31] and CCs play a critical role in determining oocyte developmental potential both before and after ovulation [32].

The interaction between cumulus-granulosa cell derived factors such as kit ligand and oocyte secreted GDF9 is essential for oocyte growth [33,34]. This dialogue between the oocyte and CCs is accomplished mainly through the gap junction type of intercellular communication [35] and the presence of this junction supports oocyte competence in vitro [36]. For instance, complete removal of CCs before in vitro maturation or blockage of gap junction inhibits oocyte maturation [37]. Similarly, inhibition of these functional coupling using gap junction inhibitors significantly reduces developmental competence [38].

Developmentally competent oocytes are selected based on the number and compactness of the surrounding CCs layers $[39,40]$ as oocytes that fail to expand their CCs can't ovulate and/or are infertile [41-44]. There is notable species level difference regarding the source and identity of cumulus expansion enabling factor (CEEF). While OSFs, like GDF9 and BMP15 are believed to be CEEF in rat [45], their presence is not mandatory for bovine [46] and porcine [47] CCs expansion in vitro as oocytectomised complexes (CC - OO) expands as equally as the intact ones.

High expression of hyaluronan synthase 2 (HAS2), inhibin beta A $(I N H \beta A)$, epidermal growth factor receptor $(E G F R)$, geremlin (GREM1), beta cellulin (BTC), cell cycle division $44(C D 44)$, tumor necrosis alpha induced protein 6 (TNFAIP6) and prostaglandin synthase 2 (PTGS2) have been associated with developmental competence of oocytes and suggested as predictors of embryo quality in women [40] and cow [48]. On the contrary, higher expressions of cysteine proteinases cathepsin $B, S, K$ and $Z$ have been associated with incompetent bovine oocytes [49].

Although studies were conducted to identify molecular biomarkers for developmentally competent bovine oocytes, large scale expression data on oocyte or CCs specific transcripts is still lacking. Removal of oocyteCCs communication axis during in vitro maturation reduces CCs expansion and thereby affects oocyte developmental competence but the effect of removing this communication axis on their gene expression is poorly understood. Furthermore, genes differentially expressed between germinal vesicle (GV) and metaphase II (MII) stage CCs are not identified and functional changes associated with those differentially expressed genes are not characterized. Identification of transcripts that are exclusively and commonly expressed between the oocyte and its companion CCs and those that are affected when the oocyte and its companion CCs mature in the presence or absence of one or the other would enhance our understanding of the molecules and biological processes that are involved in oocyte-CCs dialogue and oocyte maturation.

Therefore, this study was conducted to 1. Identify transcripts that are co and exclusively expressed between the oocyte and CCs, 2. Enumerate those which are significantly affected when the two cell types mature with or without the other and 3. Identify significantly changed biological processes during the transition of CCs from GV to MII stage.

\section{Methods}

\section{Sample collection}

Bovine ovaries were collected from local abattoirs and transported to the laboratory within 2-3 hours (hrs) in a thermo flask containing $0.9 \%$ physiological saline solution at $39^{\circ} \mathrm{C}$. Before aspiration of COCs, the ovaries were washed twice in $70 \%$ ethanol. COCs were aspirated from antral follicles having 2-8 $\mathrm{mm}$ diameter using $5 \mathrm{ml}$ syringe attached to 18 gauge needle. The aspirated follicular fluid was collected in $50 \mathrm{ml}$ sterilized tube at $35^{\circ} \mathrm{C}$ and allowed to precipitate for $15 \mathrm{~min}$. COCs with evenly granulated cytoplasm surrounded by multiple layers of CCs were picked using glass-pipette and washed three times in drops of modified parker medium (MPM) supplemented with $12 \%$ estrus cow serum (OCS).

In order to increase the homogeneity of the experimental samples, COCs were further screened for developmental competence using brilliant cresyl blue (BCB) staining as described in [50-52]. $\mathrm{BCB}$ positive $\left(\mathrm{BCB}^{+}\right)$ COCs were assigned randomly into the following four experiments. Each experiment had three pools of 
biological replicates; each replicate containing 50 oocytes or CCs samples (Figure 1). In experiment 1a, $\mathrm{CCs}$ were mechanically removed from oocytes at GV stage by repeated in and out pipetting and the resulting denuded oocytes (DOs), designated by number 1 and their companion $\mathrm{CC}$ s by number 2 , were frozen. In experiment $1 \mathrm{~b}$, intact COCs were cultured; their companion CCs were mechanically removed and the resulting denuded MII oocytes, designated by number 4 and their companion CCs by number 3, were frozen. In experiment 2, CCs were mechanically removed from their enclosed oocytes at GV stage and the resulting (OO $\mathrm{CCs})$, designated by number 5 and other intact COCs $(\mathrm{OO}+\mathrm{CCs})$ were cultured separately. After $22 \mathrm{hr}$ culture period, CCs were mechanically removed from the intact oocytes and the resulting denuded MII oocytes (number 6) were frozen. In experiment 3, oocytes were micro surgically removed from their companion CCs at GV stage as described previously $[17,46,47]$. Briefly, using micromanipulators with a holding pipette $(20 \mathrm{pm}$ diameter hole) and a fine glass needle, the complex is held under negative pressure and the oocyte pierced through both sides of the zona pellucida. The contents of the oocyte are then aspirated through the holding pipette while removing the glass needle, resulting in temporary deformation of the zona pellucida. Almost all of the oocyte contents are removed in this way, leaving an intact complex without the oocyte, the oocytectomised complex (CCs - OO). The resulting complexes (CCs - OO), designated by number 7 and other intact complexes $(\mathrm{CCs}+\mathrm{OO})$ were cultured. After $22 \mathrm{hr}$ culture, oocytes were micro surgically removed from their intact cumulus oocyte complexes ( $\mathrm{CCs}+\mathrm{OO})$, as

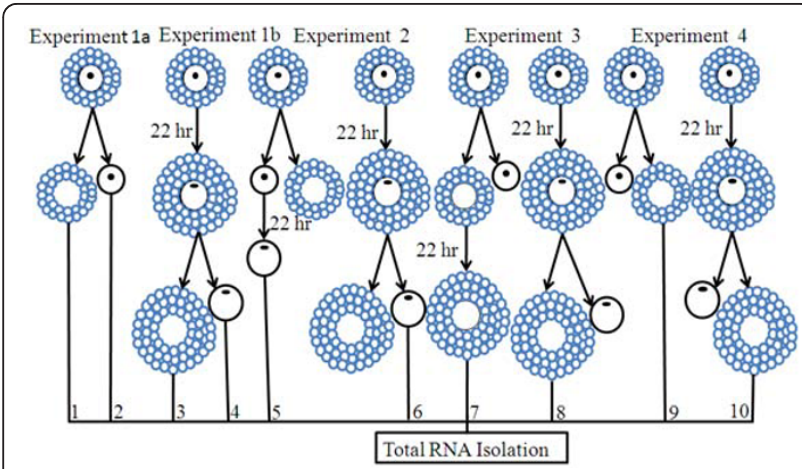

Figure 1 Diagrammatic illustration of the experimental design showing groups that were used for total RNA isolation, CDNA synthesis, array hybridization and quantitative and semiquantitative RT-PCR validation of the array data. Numbers, 1 - 10, under each oocyte and CCs figure, represent the samples that were used for RNA isolation, CDNA synthesis and array hybridisation, as explained in materials and methods section. For all experimental groups, the samples were derived from GV stage COCs. described above and the resulting MII CCs without their enclosed oocytes, designated by number 8 were frozen. In experiment 4, CCs were mechanically removed from their enclosed oocytes both at GV (number 9) and MII stages (number 10) and frozen for subsequent total RNA isolation. In both cases, cells were cultured for 22 hrs and each experiment was repeated three times. Complete removal of either cell from one or the other was confirmed by microscopic examination of the corresponding samples (Figures 2A and 2B) as described in [53]. Cells were cultured in groups of 50 in $400 \mu \mathrm{l} \mathrm{MPM}$ medium supplemented with $12 \%$ estrus cow serum and $10 \mu \mathrm{g} \mathrm{mL}^{-1} \mathrm{FSH}$ for $22 \mathrm{hr}$ at $39^{\circ} \mathrm{C}$ in an incubator with humidified atmosphere containing $5 \%$ $\mathrm{CO}_{2}$. Samples were stored at $-80^{\circ} \mathrm{C}$ until subsequent RNA isolation.

\section{RNA isolation and array processing}

In all experiments, always triplicate pools of oocytes or their corresponding $\mathrm{CCs}$ (each pool contains 50 oocytes or their corresponding CCs), were used for RNA isolation and subsequent downstream analysis. The total oocytes or CCs samples used for this study correspond to 150 oocytes or their respective CCs per each experiment.

Total RNA was isolated using PicoPure RNA Isolation Kit according to the manufacturer's instruction (Arcturus Bioscience Mt. View CA). Briefly, the samples were extracted using $100 \mu \mathrm{L}$ of extraction buffer and resuspended by pipetting gently. They were incubated for $30 \mathrm{~min}$ at $42^{\circ} \mathrm{C}$ and centrifuged at 3,000 $\times g$ for two min. One hundred $\mu \mathrm{L}$ of $70 \%$ ethanol was pipetted to the cell extract and mixed well by pipetting up and down. Two hundred $\mu \mathrm{L}$ conditioning buffer was pipetted onto the purification column filter membrane and the columns were incubated with conditioning buffer for $5 \mathrm{~min}$ at room temperature. The purification columns were centrifuged in the provided collection tube at $16,000 \times g$ for $1 \mathrm{~min}$ and $50 \mu \mathrm{L}$ of $70 \%$ ethanol was pipetted into the cell extract. The cell extract and

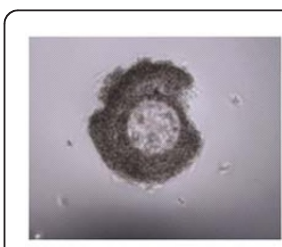

(A)

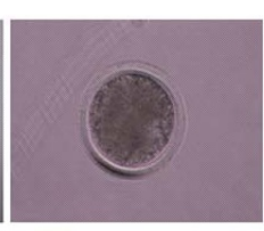

(B)

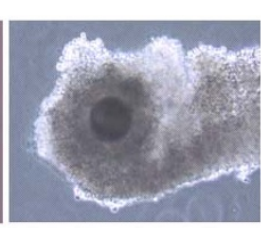

(C)
Figure 2 Representative images showing CCs from which the enclosed oocyte was completely removed at GV stage using oocytectomy $(A)$ and the oocyte from which the companion CCs were completely removed mechanically at GV stage using pipettes (B) and intact COC (C). Images were taken using Leica DM-IRB microscope with a magnification of $100 \times$. 
ethanol mixture were pipetted into the preconditioned purification column. RNA was bound to the column by centrifuging for $2 \mathrm{~min}$ at $100 \times g$, immediately followed by a centrifugation at $16,000 \times g$ for $30 \mathrm{sec}$ to remove flow through. One hundred $\mu \mathrm{L}$ wash buffer 1 was pipetted into the purification column and centrifuged for 1 minute at $8,000 \times g$. Contaminating DNA was removed by DNase treatment. One hundred $\mu \mathrm{L}$ of wash buffer 2 (W2) was pipetted into the purification column and centrifuged for $1 \mathrm{~min}$ at $8,000 \times g$. Another $100 \mu \mathrm{L}$ W2 was pipetted into the purification column and centrifuged for $2 \mathrm{~min}$ at $16,000 \times g$. The purification column was checked for any residual wash buffer by re-centrifuging at $16,000 \times g$ for $1 \mathrm{~min}$ and transferred to a new $0.5 \mathrm{~mL}$ micro centrifuge tube provided in the kit. Eleven $\mu \mathrm{L}$ of elution buffer was pipetted directly onto the membrane of the purification column and finally, the isolated total RNA was preserved in the elution buffer and used for down stream applications.

RNA quality and yield of each sample were determined using Bioanalyzer 2100 and RNA 6000 Pico LabChip assay (Agilent Technologies Inc, Palo Alto, CA) in combination with Quant-iT ${ }^{\mathrm{TM}}$ RiboGreen Reagent according to supplied protocols (Invitrogen, Carlsbad, CA). Initial total RNA concentration across all samples were adjusted to the lowly concentrated sample $(12 \mathrm{ng})$ and this amount of total RNA were used for the two round cDNA synthesis and subsequent in vitro-transcription according to the two-cycle eukaryotic target labeling assay (Affymetrix expression analysis technical manual: Eukaryotic sample and array processing http://www.affymetrix.com/ support/technical/manual/. MEGA script in vitro transcription kit containing T7-Oligo (dT) primer and other components (MEGAscript ${ }^{\circledR}$ high yield transcription kit, Applied Biosystems, Ambions) and random primers (Invitrogen, Karlsruhe, Germany) were used for the first and second cycle of cDNA synthesis. Fifteen $\mu \mathrm{g}$ of fragmented and biotin-labeled complementary RNA (cRNA) of each group were hybridized with Affymetrix bovine Genome 430 v2.0 GeneChip ${ }^{\circledR}$ arrays for $16 \mathrm{hrs}$ at $45^{\circ} \mathrm{C}$. Post-hybridization staining and washing were performed according to manufacturer's protocols using the Fluidics Station 450 instrument.

\section{Image capturing, quantification and data analysis}

Array slides were scanned with a GeneChip ${ }^{\mathrm{TM}} 3000$ laser confocal slide scanner (Affymetrix) and the images were quantified using Gene Chip Operating Software (GCOS, Affymetrix) version 1.2. Probe level data were imported into the R software environment http://www.r-project.org. Data normalization and background correction were performed using guanine-cytosine Robust Multichip Average (gcRMA) function as described in [54]. gcRMA adjusts for background intensities in Affymetrix array data which include optical noise and non-specific binding (NSB). The main function gcRMA converts background adjusted probe intensities to expression measures using the same normalization and summarization methods as RMA (Robust Multiarray Average). It uses probe sequence information to estimate probe affinity to non-specific binding (NSB). The sequence information is summarized in a more complex way than the simple GC content. Instead, the base types (A,T,G or C) at each position (1-25) along the probe determine the affinity of each probe. The parameters of the position specific base contributions to the probe affinity are estimated in an NSB experiment in which only NSB but no gene-specific binding is expected.

The presence or absence of genes were detected using microarray suit 5 (MAS 5, Affymetrix) as described in $[42,55]$. To minimize false positive signals, genes called absent were avoided and these called present in at least two of the three replicates were used for further analysis. Differential gene expression was analyzed using linear models for microarray (LIMMA) as described in [56]. LIMMA is a package for differential expression analysis of data arising from microarray experiments. The package is designed to analyze complex experiments involving comparisons between many RNA targets simultaneously while remaining reasonably easy to use for simple experiments. The central idea is to fit a linear model to the expression data for each gene. The expression data can be log-ratios, or sometimes logintensities, from two colour microarrays or log-intensity values from one channel technologies such as Affymetrix. The MIAME guidelines with details of sample preparation, experimental design, array processing and hybridization, measurements and normalisation controls are given in additional file 1 .

Differentially expressed genes in experiments $1 \mathrm{~A}$ and $\mathrm{B}$ were classified according to their gene ontology (GO) using GO consortium [57] and lists of genes over expressed in $\mathrm{OO}+\mathrm{CCs}$ and $\mathrm{CCs}+\mathrm{OO}$ relative to those expressed in OO - CCs and CCs - OO respectively, were uploaded into Ingenuity Pathways Analysis (IPA), (Ingenuity Systems, http://www.ingenuity.com) to identify relationships between the genes of interest and to uncover common processes and pathways in the positive phenotypes. IPA is a web-based software application that enables the modelling and analysis of biological systems using microarray data.

\section{Validation of the microarray data using semi quantitative and quantitative real time RT-PCR}

Array data was validated using real time quantitative reverse transcription PCR (qRT-PCR). For this, additional pools of biological replicates representing independent oocytes and CCs samples $(n=150)$ were used for total RNA isolation and cDNA synthesis. In order to 
reduce the variability in the concentration of the initial RNA populations across samples and to use

equivalent RNA quantities to the ones used for array hybridization, $12 \mathrm{ng}$ of the total RNA of each sample was used for cDNA synthesis using oligo (dt)25 and random primer as described elsewhere [58]. The ABI prism $^{\circledR} 7000$ apparatus (Applied Biosystems) was used to perform the quantitative analysis using SYBR $^{\circledR}$ Green Jumpstart ${ }^{\mathrm{TM}}$ Tag Ready Mix ${ }^{\mathrm{TM}}$ (Sigma) incorporation for dsDNA specific fluorescent detection dye. Standard curves were fitted for both target genes and internal control (18S rRNA) using serial dilutions of plasmid DNAs containing $10^{1}-10^{9}$ molecules and run in separate wells. PCR was assembled using $20 \mu \mathrm{l}$ total reaction volume containing double distilled (dd) water, forward and reverse primers, SYBR green universal master mix (Sigma) and $2 \mu \mathrm{l}$ template cDNAs using five replicates for each sample. During each reaction, samples from the same cDNA were run in duplicate to control the reproducibility of the results. A universal thermal cycling parameter (initial denaturizing step at $95^{\circ} \mathrm{C}$ for $3 \mathrm{~min}$, 45 cycles of denaturizing at $95^{\circ} \mathrm{C}$ for $30 \mathrm{sec}$ and $58^{\circ} \mathrm{C}$ for $30 \mathrm{sec}$ were used to quantify mRNA expression level. After the end of the last cycle, dissociation curves were fitted by starting the fluorescence acquisition at $60^{\circ} \mathrm{C}$ and taking measurements every $7 \mathrm{sec}$ interval until the temperature reaches $95^{\circ} \mathrm{C}$. Final quantitative analysis was done using relative standard curve method and the expression values of the target transcripts were normalized to that of $18 \mathrm{~S}$. The mean normalized data were reported as the amount of a given target gene transcript in the two samples compared and significantly different means were identified using t-test (SPSS Inc. Chicago, IL, USA). Pairs of primers that were used for array validation are shown in Table 1.

The appropriateness of $18 \mathrm{~S}$ as internal control was confirmed by the results of semi-quantitative RT-PCR showing its stability across all samples.

\section{Immunofluorescence staining}

In order to localize the proteins of some differentially expressed transcripts, ovarian sections were washed three times in PBS and fixed in $4 \%(w / v)$ Paraformaldehyde overnight at $4^{\circ} \mathrm{C}$. The fixed specimens were permeabilized during $2.5 \mathrm{hr}$ incubation in $0.5 \%(\mathrm{v} / \mathrm{v})$ Triton-X100 (Sigma) in PBS. To inhibit NSB of the antibodies, samples were subsequently blocked in $3 \%(\mathrm{w} / \mathrm{v})$ bovine serum albumin (BSA) in PBS for $1 \mathrm{hr}$. The sections were then incubated for $1 \mathrm{hr}$ at $39^{\circ} \mathrm{C}$ and mounted onto glass slides with gelvatol. The primary antibody for IRF6 (rabbit anti-human polyclonal antibody, Santa Cruz Biotechnologies Inc., Germany) was used at 1:100 in PBS and for MSX1 (rabbit anti-human polyclonal antibody, Lifespan Biosciences, USA) at 1:50 in blocking solution. The samples were incubated for 15 and $1 \mathrm{hr}$ with primary and secondary antibodies (FITC conjugated goat anti-rabbit secondary antibody (Lifespan Biosciences, USA), respectively using 1:100 ratio in both cases. Negative controls were processed in the same manner by omitting the use of primary antibody. In order to visualize the nucleus, the sections were finally incubated in $0.1 \mathrm{mg} / \mathrm{ml} \mathrm{4}$-6-Diamidino-2-phenylindole (DAPI, Sigma) or propidium iodide (Sigma). After the final wash in PBS, the sections were mounted on glass slides and visualized on ApoTome microscope (ApoTome MicroImaging, Inc., Carl-Zeiss, Germany).

\section{Results}

\section{Specific transcription programs are exhibited by bovine oocytes and CCs}

In order to get an insight into specific transcription program in bovine oocytes and CCs, we analyzed transcriptome profile of GV (number 1) and MII (number 4) oocytes and their companion CCs (number 2 and 3, respectively) using MAS 5 present or absent call as described elsewhere $[42,59]$. The raw data from all arrays are available online at http://www.ncbi.nlm.nih.gov/geo/ with GEO accession number GSE21005. The analysis showed that of 13162 detected genes, 1516 and 2727 are exclusively expressed in GV oocytes (number 1) and their companion CCs (number 2), respectively while 8919 are expressed in both (Additional files, 2, 3 and 4). Similarly, of 13602 detected genes, 1423 and 3100 are expressed exclusively in MII oocytes (number 4) and their companion CCs (number 3), respectively and 9079 are expressed in both (Additional files, 5, 6 and 7). In addition, expression analysis of these detected genes showed that a total of 8612 transcripts are differentially expressed between GV oocytes (number 1) and CCs (number 2) of which 4304 and 4308 are over expressed in oocytes and CCs, respectively (Additional file 8). Similarly, a total of 8863 transcripts are differentially expressed between MII oocytes (number 4 ) and CCs (number 3) of which 4271 and 4592 were over expressed in MII oocytes and CCs, respectively (Additional file, 9). The heat map and hierarchical clustering of some of the top differentially expressed genes between oocytes and $\mathrm{CCs}$ at the two stages are presented in Figures 3A and 3B and $4 \mathrm{~A}$ and $4 \mathrm{~B}$.

The GO categories (biological and molecular functions) of transcripts over expressed in GV oocytes and CCs relative to each other are shown in Figure 5 and additional file 10, respectively. The most significantly changed molecular and cellular functions associated with genes over expressed in MII CCs relative to their enclosed oocytes and vice versa are also shown in additional file 11. 
Table 1 Pairs of primers that were used for validation of array data

\begin{tabular}{|c|c|c|c|c|c|}
\hline Gene name & Accession number & Forward $\left(5^{\prime}-3^{\prime}\right)$ & Reverse $\left(3^{\prime}-5^{\prime}\right)$ & $\begin{array}{c}\text { Annealing } \\
\text { temperature }\left({ }^{\circ} \mathrm{C}\right)\end{array}$ & Product length (bp) \\
\hline GDF9 & NM_174681 & AGCGCCCTCACTGCTTCTATAT & ACACCCTCAGCAGCTTCTTCTC & 57 & 152 \\
\hline MSX1 & NM_174798 & AAGGTATCCACAGTCCCCAGC & TCTGCCTCTCCTGCAAAGTTC & 56 & 180 \\
\hline IRF6 & NM_001076934 & GGACTCCAAACGCTTCCAGA & TCCTTGGTGCCATCATACATCA & 54 & 212 \\
\hline SPARC & NM_174464 & CGATGATGGTGCTGAGGAAA & TGGTGGCAAAGAAGTGGCA & 53 & 220 \\
\hline HPSE & NM_1744082 & ATGGGCATAGAAGTGGTGATGA & TGTTGGGTMTTGTGCAATGAA & TD 54-50 & 202 \\
\hline DGAT2 & NM_205793 & TGAACCGGGACACCATAGACTA & САCCTCATTCTCCCCAAAGGA & 55 & 205 \\
\hline sox2 & NM_001105463 & GCGGCAACCAGAAGAACAG & GCTTCTCCGTCTCGGACAAA & 55 & 170 \\
\hline HAS2 & NM_174079 & CCAAATGAAATGCCAAAGGAA & CAACGTCAACCAAGCTTCACA & TD 54-50 & 237 \\
\hline PTX3 & NM_001076259 & TTATTCCCCATGCGTTCCA & CTCCACCCACCACAAGCATT & 53 & 205 \\
\hline IGF2BP3 & XM_588560 & GACGCGAAAGTGAGGATGGT & TGCACTTGACAAATTCTGGAGC & 54 & 215 \\
\hline ADAMTS1 & NM_001101080 & TCGTCATACAGCTCCCCTCC & ATTGACACACCATTTCCCCTCT & TD 57-54 & 220 \\
\hline PDK4 & XM_583960 & ATTाTGCGACAAGAGTTGCCT & GGATTCCTTGTGCCATTGTAGG & TD 56-52 & 250 \\
\hline CCRK & XM_879150 & GGCCCCACTCATGGCTACTT & TCCTGAGGGTGATGCTGGTAA & 57 & 170 \\
\hline FOSB & XM_880646 & TTCCTGAATCTCTCCCGCC & TGCTCACAGCCTCACACTCG & 56 & 205 \\
\hline POU5F1 & NM_174580 & AGAAGGGCAAACGATCAAGC & GGTGACAGACACCGAGGGAA & TD 57-53 & 205 \\
\hline VEGFA & NM_174216 & GGTTCGGGAACCAGACGT & GGCAATCCAATTCCAAGAGGA & 55 & 233 \\
\hline 185 & NR_003286 & GTGCCCTTCCGTCAATTCCT & ACGAAAGTCGGAGGTTCGAA & 55 & 184 \\
\hline GPT & XM_585516 & CCGATGAGGTGTACCAAGACAA & СCATATTCACCACCTCCACGT & 55 & 185 \\
\hline DAPL1 & NM_001025346 & AAATTTCCAGCAGTAGCGCAC & AGCTCTCAGACATTCGAGGCA & 55 & 158 \\
\hline IRF7 & NM_001105040 & CTCCCCGCACTACACCATCTA & GCCTGTTCCACCTCCATCA & TD 58-55 & 245 \\
\hline GADD45A & NM_001034247 & GACCGAAAGGATGGATAAGGTG & TGGATCAGGGTGAAGTGGATCT & 56 & 200 \\
\hline DPP4 & NM_174039 & CAACTGGGCTACTTACCTTGCA & TTACGTACCCTCCGTATGACCA & 56 & 223 \\
\hline$|\mathrm{F}| 6$ & NM_001075588 & ACGGTGACAAAGCCTTGAGC & AGGTCACCATGCCCCAGAA & 55 & 158 \\
\hline ADAMTS4 & NM_181667 & CCATTGTGGAGGATGATGGG & AGGAAGTCAGTGATGAAGCGG & 55 & 210 \\
\hline CASP1 & XM_592026 & CTCACTCAGAGCATCGGACCT & GTITACCCATACCATCCCTTGC & 57 & 229 \\
\hline IFIT5 & NM_001075698 & CACAGTGTATCGGCTGGATGA & GGTTGGGCTGATATCTGGTCC & 56 & 200 \\
\hline DDX39 & NM_001034752 & GCAGTTCAAGGACTTCCAGC & GCTCTGCCACATTCACTTCA & TD 55-52 & 228 \\
\hline GTF2A2 & NM_001037619 & AGAAAGAGGTTCTGCCCGGA & CTTATCGGCTGCATTGAAAGC & 55 & 150 \\
\hline TSSC1 & XM_001789233 & AGCAGCGACAGCAGAGTCATC & TAGCTCAGGGAGGCGAACAG & 57 & 229 \\
\hline FSHR & NM_174061 & GCTGGATCTITGCTIITGCAGT & ATGCGCTTGGCTATCTTGGT & 54 & 243 \\
\hline GPT & NM_001083740 & CCGATGAGGTGTACCAAGACAA & СCATATTCACCACCTCCACGT & 56 & 185 \\
\hline PLAUR & NM_174423 & GGATTCCACAACAACCACACCT & TCGCTTCCAGACATTGATTCAT & TD 56-52 & 204 \\
\hline CA2 & NM_178572 & CAAAGCAGTGCTGAAAGATGGA & AAAACACCCACAACAGCCAGTC & 55 & 212 \\
\hline
\end{tabular}

Touch down $(T D)=$ The forward and the reverse primers of a given gene have different annealing temperatures.

\section{Removal of oocyte or CCs at GV alters the gene expression of either cell at MII stage}

In order to investigate transcriptome profile changes when the oocyte matures with or without its companion CCs and when CCs mature with or without their enclosed oocytes, we analyzed their corresponding transcriptome profiles using LIMMA as described previously [56]. The analysis showed that a total of 265 genes are differentially expressed between $\mathrm{OO}+\mathrm{CCs}$ (number 5) and OO-CCs (number 6) of which 217 and 48 are over expressed in $\mathrm{OO}+\mathrm{CCs}$ and $\mathrm{OO}$ - CCs, respectively (Additional file 12).

Similarly, 566 genes are differentially expressed between $\mathrm{CCs}$ that were cultured with (CCs $+\mathrm{OO})$ (number 7) or without their enclosed oocytes (CCs - OO) (number 8) of which 320 and 246 are over expressed in $\mathrm{CCs}+\mathrm{OO}$ and
CCs - OO, respectively (Additional file 13). Hierarchical clustering and heat map of the top differentially expressed genes between $\mathrm{OO}+\mathrm{CCs}$ and $\mathrm{OO}-\mathrm{CCs}$ and between $\mathrm{CCs}+\mathrm{OO}$ and $\mathrm{CCs}-\mathrm{OO}$, with a fold change of $>4$ and 16, are presented in Figures 6 and 7, respectively.

We found that 36 and 375 of these genes over expressed in $\mathrm{OO}+\mathrm{CCs}$ and $\mathrm{CCs}+\mathrm{OO}$, respectively, could be assigned to a specific functional group based on the information in the IPA Knowledge Base. Only 4 of the mapped genes over expressed in $\mathrm{OO}+\mathrm{CC}$ group, representing about $1.5 \%$ of the total, are classified under the functional group "Carbohydrate metabolism," which contains genes involved in energy conversion and modulation. Other functional groups, including molecular transport, nucleic acid metabolism, small molecule biochemistry and RNA 


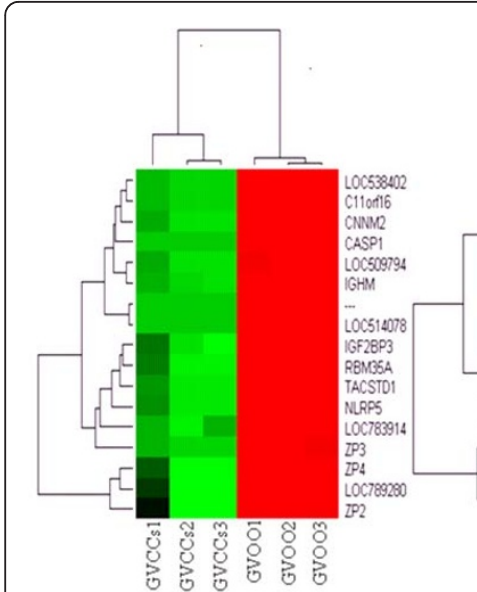

(A)

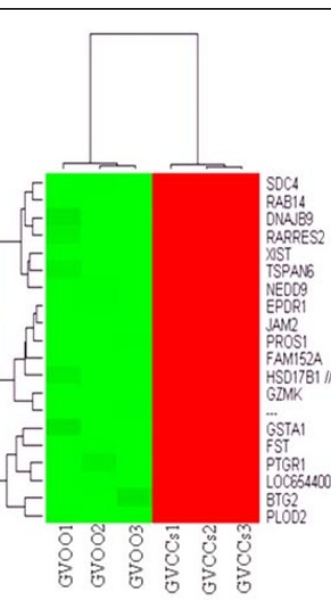

(B)
Figure 3 Hierarchical clustering and heat map of some of the top genes over expressed in GV oocytes (A) and CCs (B) with a fold change of more than 1024. Abbreviations, GVOO and GVCCS stand for germinal vesicle oocyte and cumulus cells, respectively. Numbers (1, 2, and 3$)$ indicate the three biological replicates used for microarray hybridization. post transcriptional modification are also observed. Similarly, 90 of the genes over expressed in CCs + OO, representing $34 \%$ of the total are classified under cellular growth and proliferation. A graphical representation of this functional classification of the genes over expressed in $\mathrm{OO}+\mathrm{CCs}$ and $\mathrm{CCs}+\mathrm{OO}$ are shown in Figures 8 and 9, in which 16 and 12 functional groups with higher $P$-values are noted. Some of these groups shared several common genes. In addition, 28 and 23 of the genes over expressed in $\mathrm{OO}+\mathrm{CCs}$ and $\mathrm{CCs}+\mathrm{OO}$ relative to $\mathrm{OO}-\mathrm{CCs}$ and CCs - OO respectively, are assigned to 5 and 8 different canonical pathways (Additional files 14 and 15). Finally, these genes from the two groups were mapped on 5 top networks each network containing genes from the input data that shared known direct or indirect relationships. Examples of networks created from our data are shown in Figures 10 and 11, where the relationships between molecules that were over expressed in $\mathrm{OO}+\mathrm{CCs}$ and $\mathrm{CCs}+$ $\mathrm{OO}$ are represented by the arrows that connect them. Figure 10 shows a complex network that plays an important role in gene expression, small molecule biochemistry and

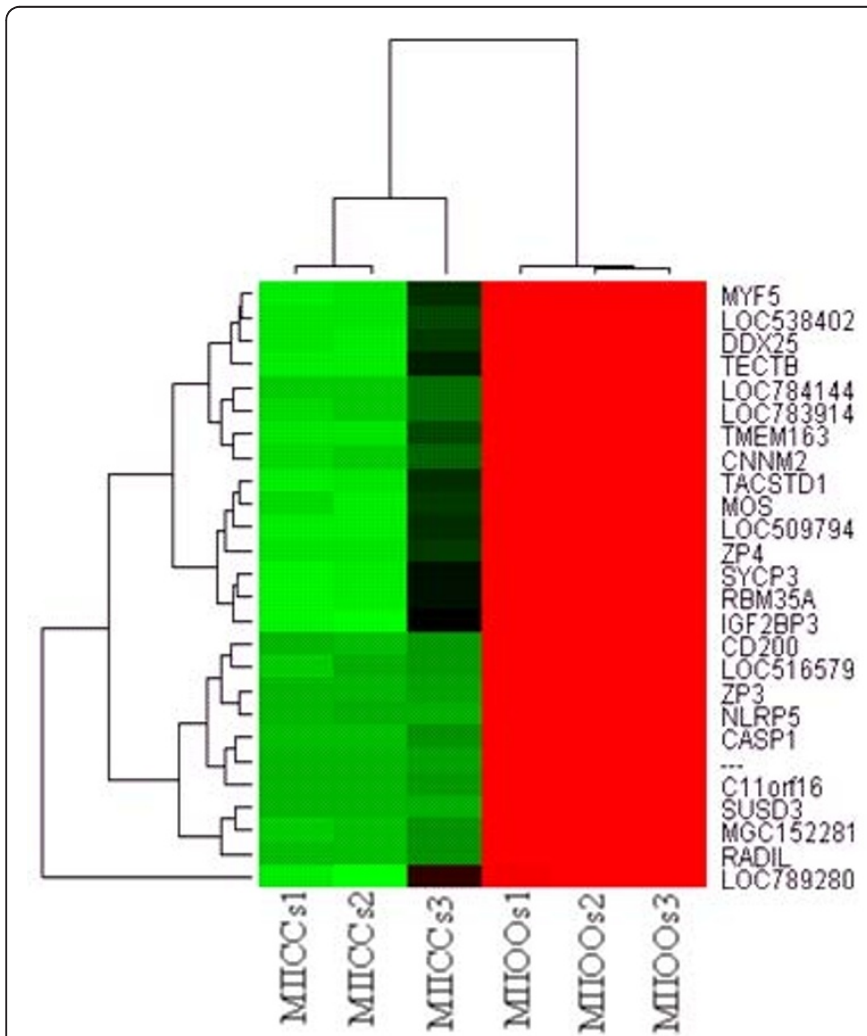

(A)

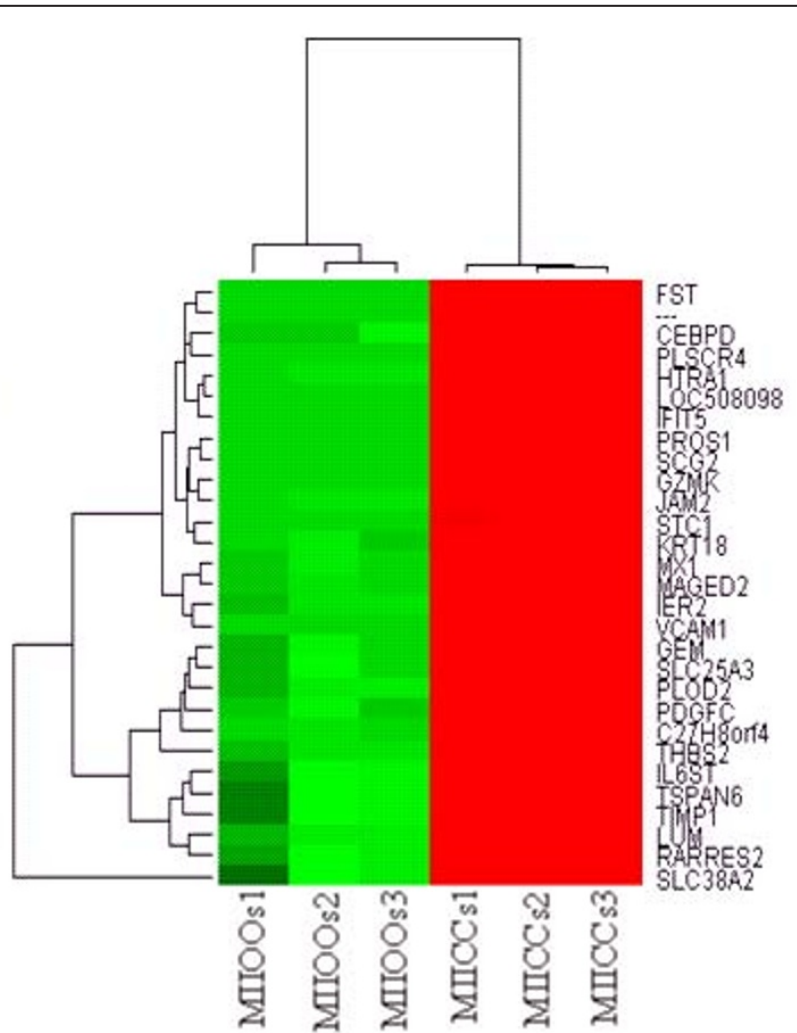

(B)

Figure 4 Hierarchical clustering and heat map of some of the top over expressed genes in MIl oocytes (A) and CCs (B) with a fold change of more than 512. Abbreviations, MIIOO and MIICCS stand for metaphase II oocyte and cumulus cells, respectively. Numbers (1, 2, and 3) indicate the three biological replicates used for microarray hybridization. 


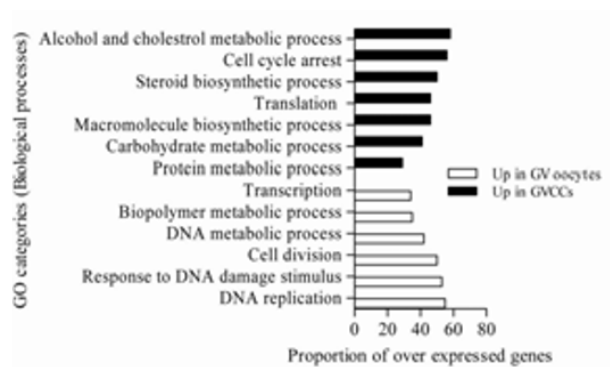

Figure 5 The top significantly changed GO terms (biological processes) with the proportion of transcripts involved among those over expressed in GV oocytes and CCs. The proportion of transcripts in a GO term was calculated as the number of genes over expressed in one sample divided by the total number of genes that are involved in that given $\mathrm{GO}$ term multiplied by $100(\mathrm{P}<0.001)$.

carbohydrate metabolism while Figure 11 shows a network that plays a role in cellular development.

\section{Global transcriptome changes in the CCs and associated} functional changes during COCs in vitro maturation In this experiment we analyzed global transcriptome changes during the transition of CCs from GV (number

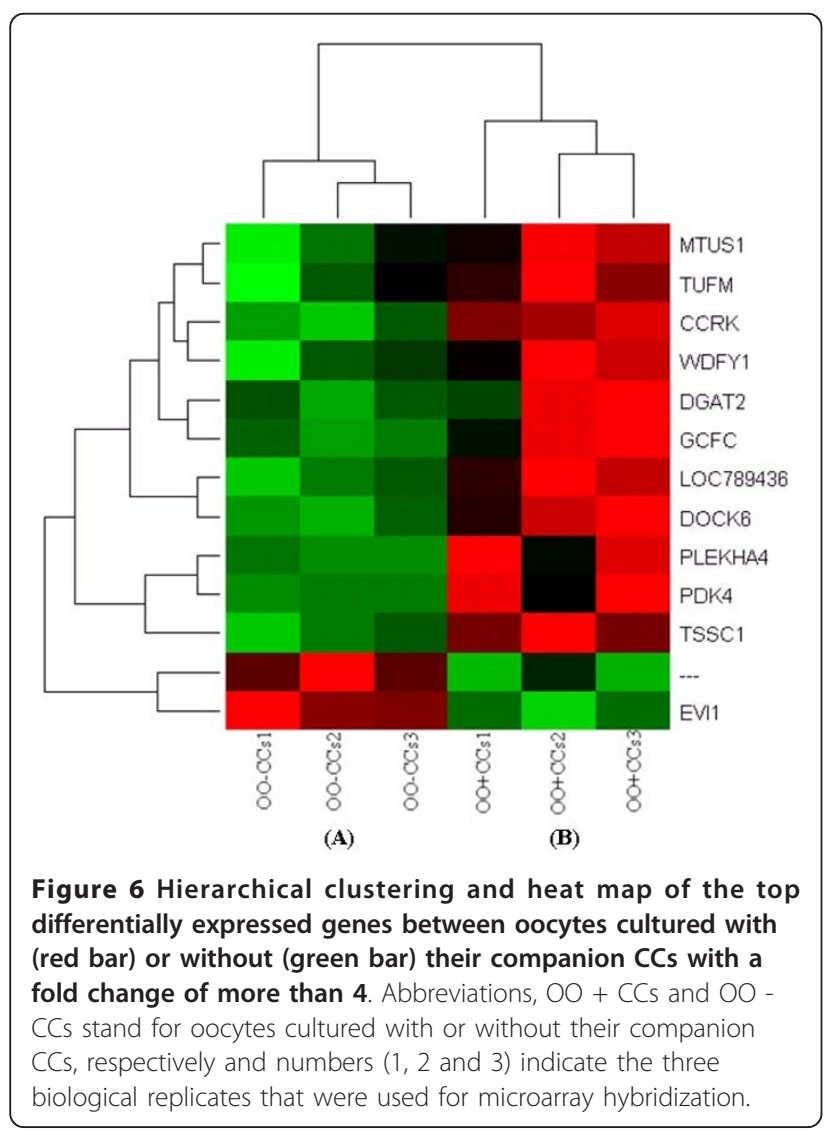

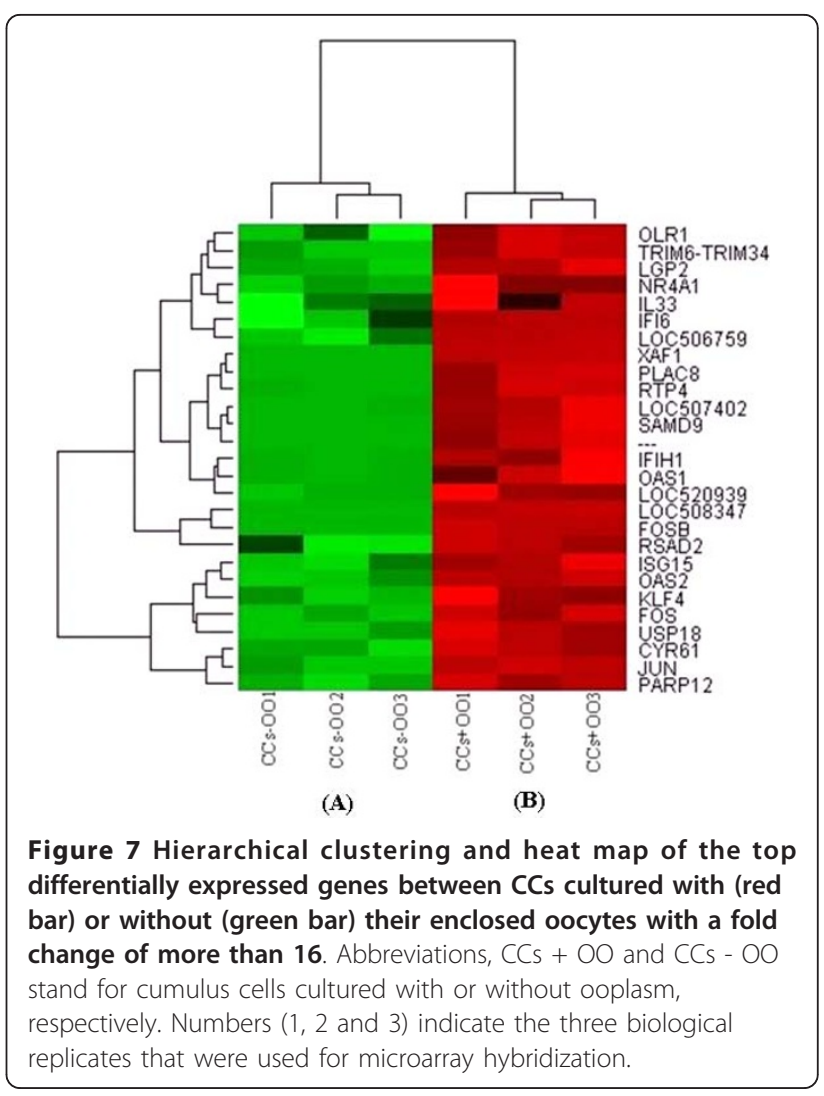

9) to MII (number 10) stage. The results of MAS 5 present and absent call showed that of 12827 detected genes 4689 and 834 are exclusively expressed in GV and MII CCs, respectively, while 7304 are expressed commonly at both stages (Additional files, 16, 17 and 18). Additionally, expression analysis of these detected genes showed that a total of 4677 genes are differentially expressed between the two samples of which 2397 and 2280 are over expressed in GV and MII stages, respectively (Additional file 19). The heat map and hierarchical clustering of the top differentially expressed genes (fold change > 256), GO categories (biological processes and cellular and molecular functions) between the two CCs stages are shown in Figures 12, 13 and 14, respectively.

\section{Validation of the microarray data using quantitative and} semi quantitative real time RT-PCR

In order to validate the micro array data, a total of 23 transcripts were quantified using qRT-PCR as described in materials and methods section. The assayed genes are selected based on the criteria of being abundant at significantly higher level or their exclusive abundance in either of the samples considered in the array analysis. Transcripts Semi-quantitative RT-PCR was also adopted to validate some genes that are exclusively expressed either as the oocyte or CC transcripts. With the 


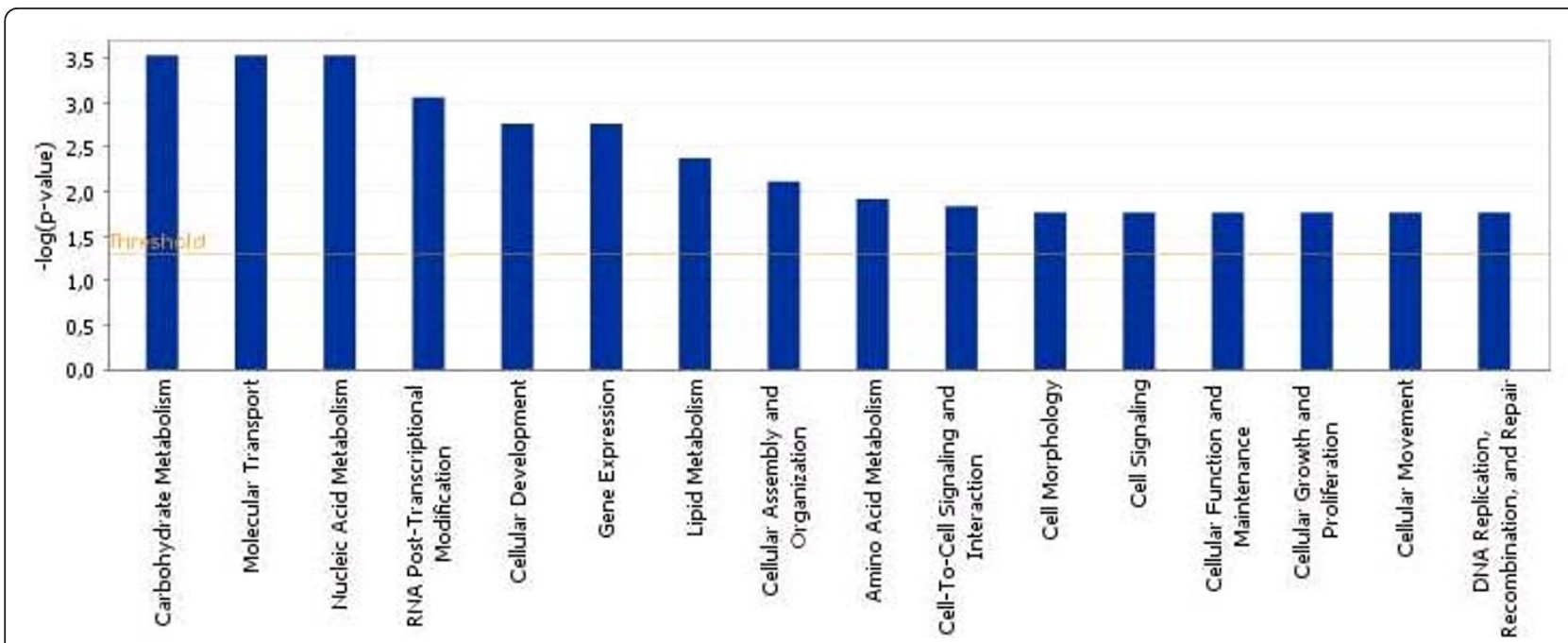

Figure 8 Functional grouping of genes that are over expressed in the $00+$ CCs relative to $00-$ CCs samples showing the most significant functional groups, with P values, $\mathbf{0 . 0 5}$. The bars represent the P-value in logarithmic scale for each functional group.

exception of one transcript, the results of qRT-PCR analysis validated the array data as the expression levels of a given transcript between the two samples compared (designated by *) are significantly different $(\mathrm{P}<0.05)$ (Figures 15, 16, 17, 18, 19). Additionally, semi-quantitative RT-PCR validation of some selected genes also supports the microarray data (Figure 20). The actual microarray expression values of genes validated using real time qRT-PCR analysis are shown as additional files 20, 21, 22, 23 and 24.
Immunoflourescence staining for localization of two selected proteins, IRF6 and MSX1, in oocyte or CCs clearly demonstrated that IRF6 is expressed only in oocyte and MSX1 is expressed in both oocyte and CCs showing the accuracy of our hybridization protocol (Figure 21).

\section{Discussion}

We analyzed the transcriptome profiles of bovine oocytes and their companion CCs and investigated

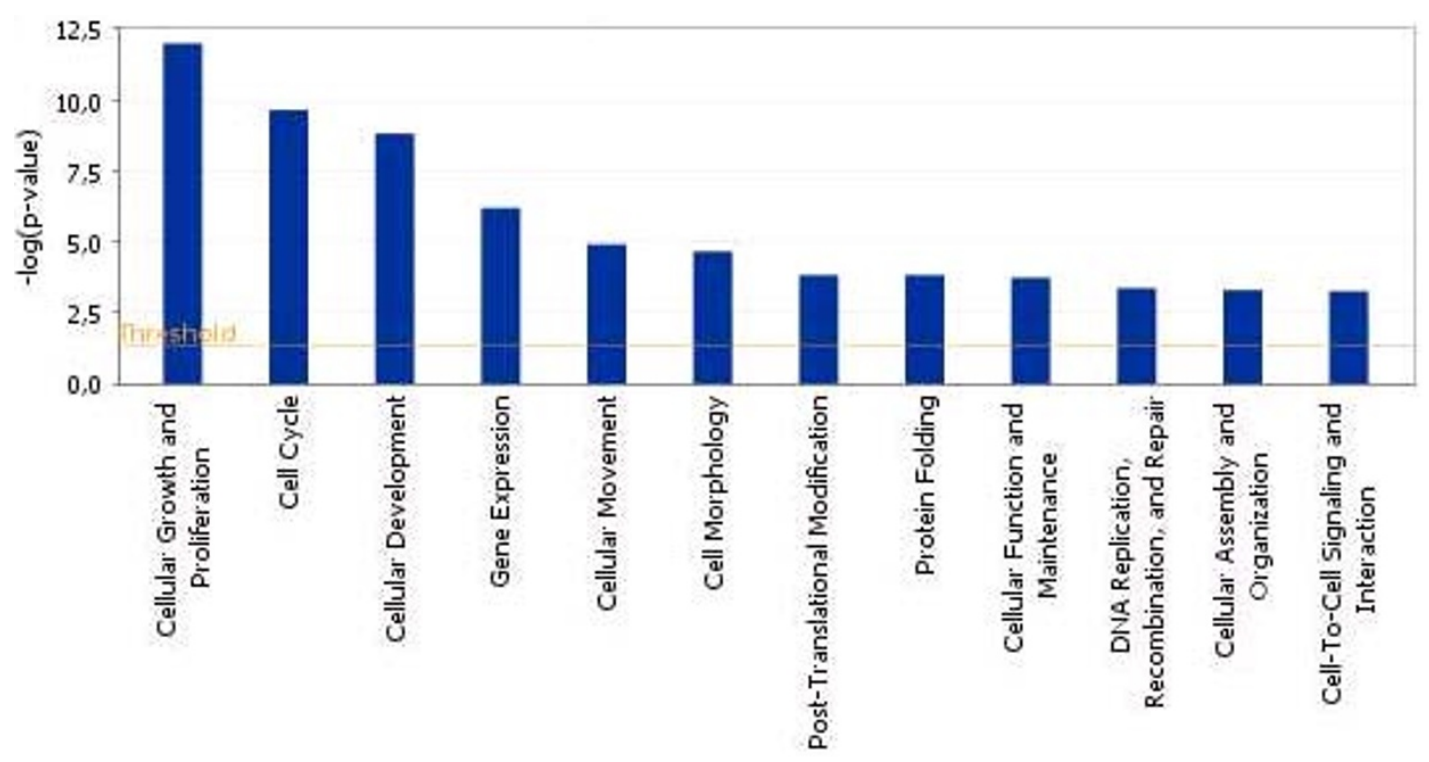

Figure 9 Functional grouping of genes that are over expressed in the CCs + OO relative to CCs - OO samples showing the most significant functional groups, with P values, $\mathbf{0 . 0 5}$. The bars represent the P-value in logarithmic scale for each functional group. 


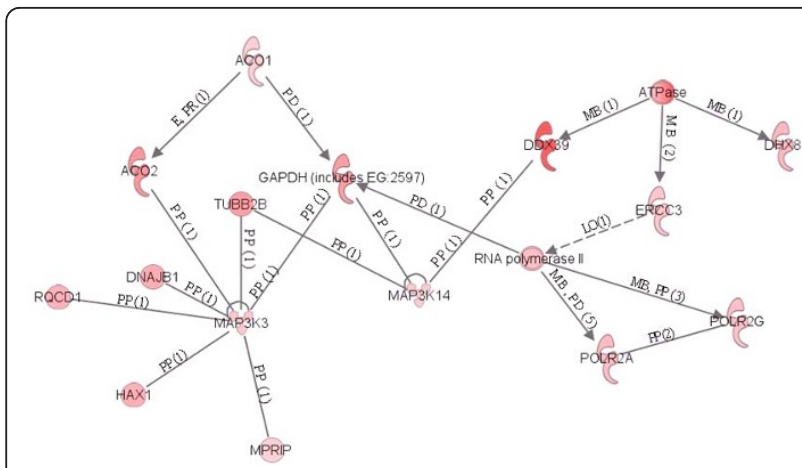

Figure 10 An example of a gene network, showing the relationships between molecules identified by the microarray and over expressed in oocytes cultured with their companion CCs. The type of the association between two molecules is shown as a letter on the line that connects them. The number in parenthesis next to the letter represents the number of bibliographic references currently available in the Ingenuity Pathways Knowledge Base that support each one of the relationships. Direct or indirect relationships between molecules are indicated by solid or dashed lines connecting them, respectively. $\mathrm{P}=$ phosphorylation, $\mathrm{A}=$ gene activation, $\mathrm{E}=$ increase in expression, $\mathrm{PP}=$ protein-protein interaction, $\mathrm{PD}=$ protein-DNA binding, $\mathrm{MB}=$ membership in complex, $\mathrm{LO}=$ localization, $\mathrm{L}=$ proteolysis, $\mathrm{RB}=$ regulation of binding.

transcriptome profile changes when either cell type matures with or without the other using Affymetrix GeneChip Bovine Genome Array. Here, we identified for the first time, transcripts that are exclusively expressed in bovine oocytes or CCs at GV and MII stages. Identifying specific transcription programs either in oocyte or CCs has a paramount importance in RNAi based gene function study. Knowledge of genes exclusively expressed either in oocyte or CCs would enable researchers to select the appropriate design for functional analysis of genes and route of introducing RNAi agents into COC. For instance, if a given gene is expressed only in CCs, transfection is the best method of introducing anti-sense oligomers into the complex. Identification of such genes would help also in understanding functional biological processes and pathways specific to either oocyte or CCs.

Additionally, we assessed the effect of removing the bi-directional communication axis on the gene expression profile of either cell during in vitro maturation and transcriptome profile changes associated with the transition of CCs from GV to MII stage at global scale. Identification of genes that are significantly affected when either the oocyte or CCs mature with or without one or the other would be vital to understand the most important cellular and molecular functions that are associated with the acquisition of developmental competence.

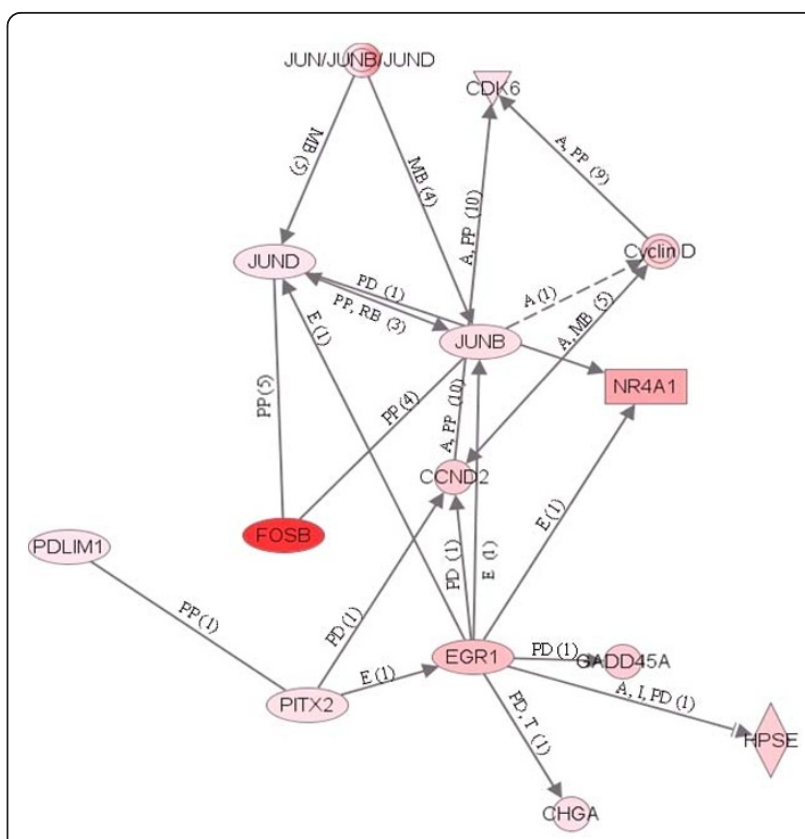

Figure 11 An example of a gene network, showing the relationships between molecules identified by the microarray and over expressed in CCs cultured with the enclosed oocytes relative to those cultured without. The type of the association between two molecules is shown as a letter on the line that connects them. The number in parenthesis next to the letter represents the number of bibliographic references currently available in the Ingenuity Pathways Knowledge Base that support each one of the relationships. Direct or indirect relationships between molecules are indicated by solid or dashed connecting lines, respectively. $\mathrm{P}=$ phosphorylation, $\mathrm{A}=$ gene activation, $\mathrm{E}=$ increase in expression, $\mathrm{PP}=$ protein-protein interaction, $\mathrm{PD}=$ protein-DNA binding, $\mathrm{MB}=$ membership in complex, $\mathrm{LO}=$ localization, $L=$ proteolysis, $\mathrm{RB}=$ regulation of binding.

\section{Specific expression program is exhibited by bovine oocyte and CCs}

In addition to the previously identified ones [42,59], this study identified several oocyte or CCs specific transcripts that may play important biological roles in the bi-directional communication of the two cell types during in vitro maturation and for the acquisition of developmental competence at latter stages. Hierarchical clustering of differentially expressed genes demonstrated that the expression profile of oocyte is markedly different from that of its companion CCs with the latter having more number of transcripts than the former.

Transcripts that are over expressed in oocytes are involved in processes leading to meiotic maturation. We found considerably higher (more than 1024 fold change) and exclusive expression of GDF9, BMP15, MOS, Zona Ppellucida Proteins (ZP2, 3, 4), NLRP5, RBM35A, TACSTD1, GAS7 and others in oocyte compared with CCs. Since the roles of GDF9 and BMP15 in oocyte 


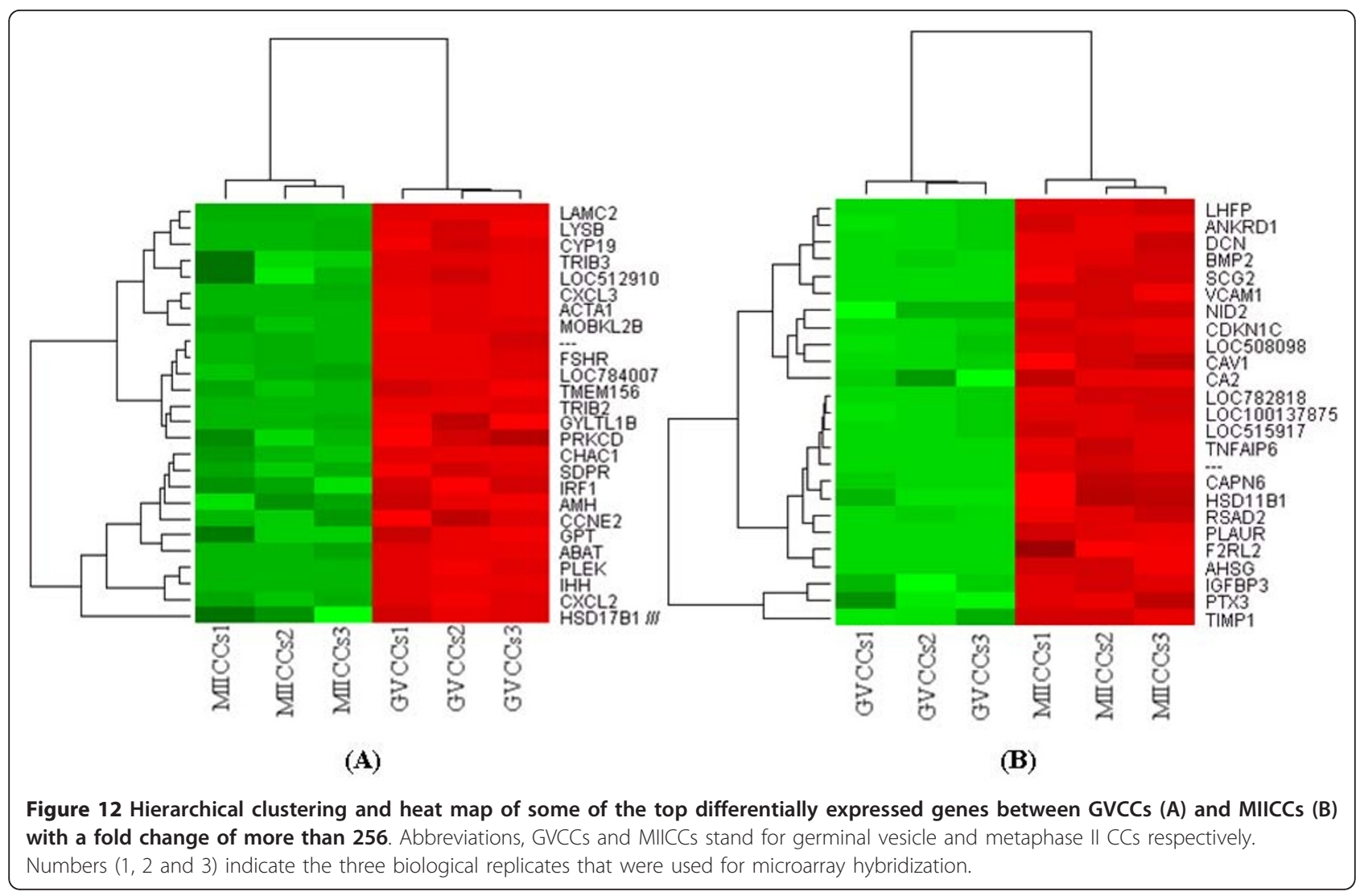

growth and maturation have been widely addressed $[2,60,61]$ we are not going to discuss them here. The c-mos proto-oncogene product MOS is believed to be an active component of the cytostatic factor that stabilizes and sustains the activity of maturation-promoting factor (MPF). Notable interspecies differences exist among

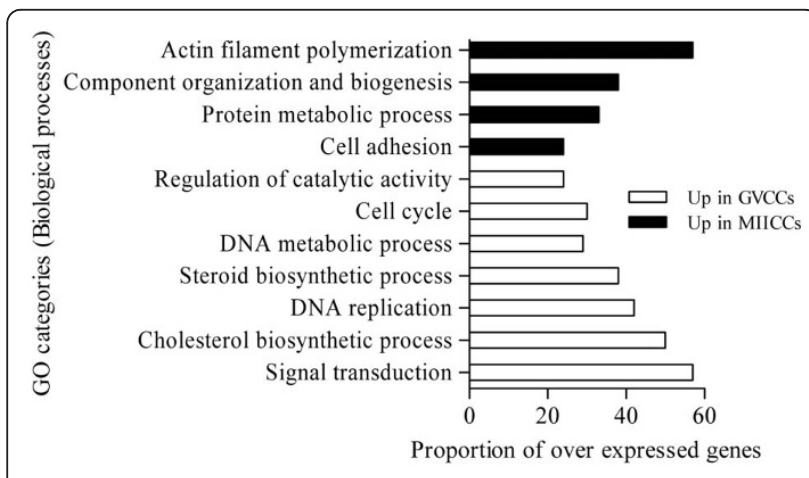

Figure 13 The top significantly changed GO terms (biological processes) with the proportion of transcripts involved among these over expressed in GV and MIICCs relative to each other. The proportion of transcripts in a GO term was calculated as the number of genes over expressed in one sample divided by the total number of genes that are involved in that given $\mathrm{GO}$ term multiplied by $100(P<0.001)$. different vertebrates regarding the physiological effects of MOS on oocyte maturation. Its higher expression in oocytes both at GV and MII stages in the current study supports previous claims that MOS is required both for the activation of MPF during meiosis I and II and for the meiotic arrest at meiotic MII $[62,63]$.

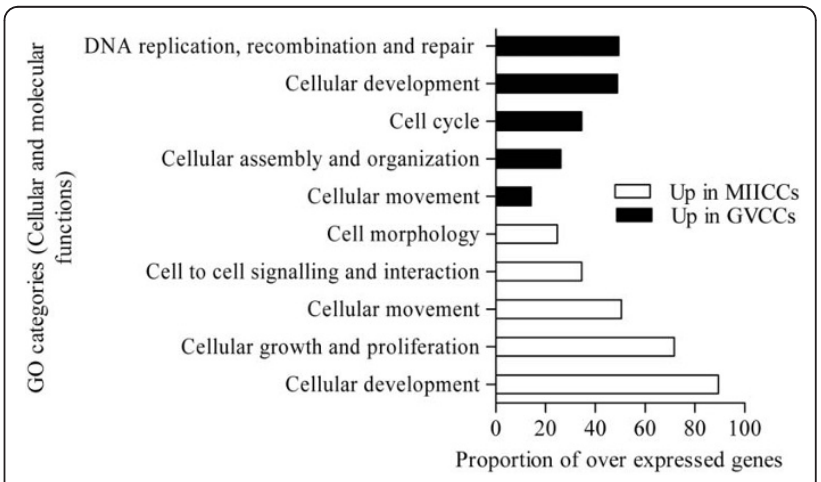

Figure 14 The top significantly changed GO terms (cellular and molecular functions) with the proportion of transcripts involved among these over expressed in GV and MII CCS relative to each other. The proportion of transcripts in a GO term was calculated as the number of genes over expressed in one sample divided by the total number of genes that are involved in that given $\mathrm{GO}$ term multiplied by $100(\mathrm{P}<0.001)$. 


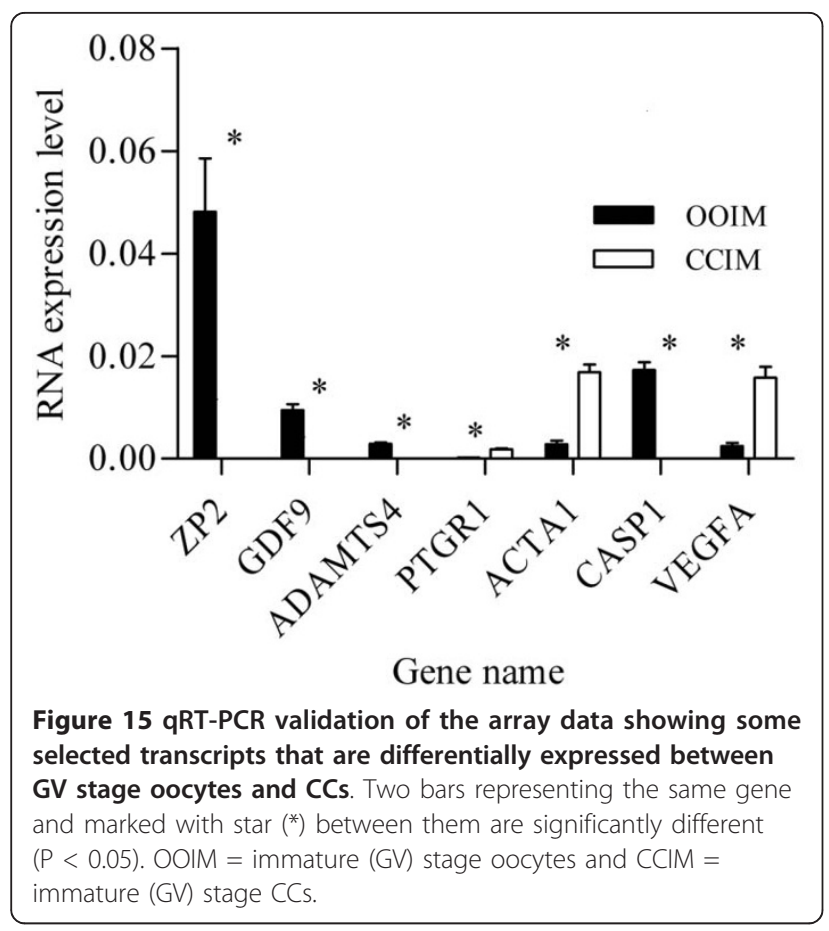

Trans-membrane proteins are involved in oocytegranulosa cell regulatory loop and Rho proteins play a role in GTP-bound active state and can interact with a number of effectors to transduce signals leading to diverse biological responses including actin cytoskeletal

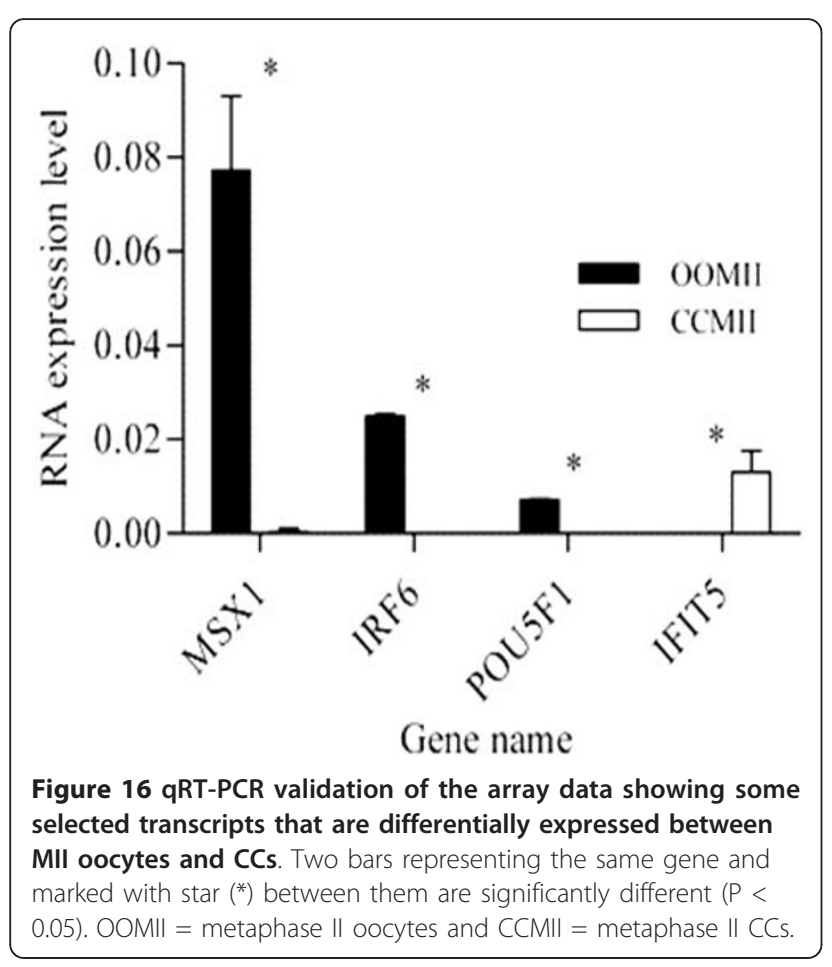

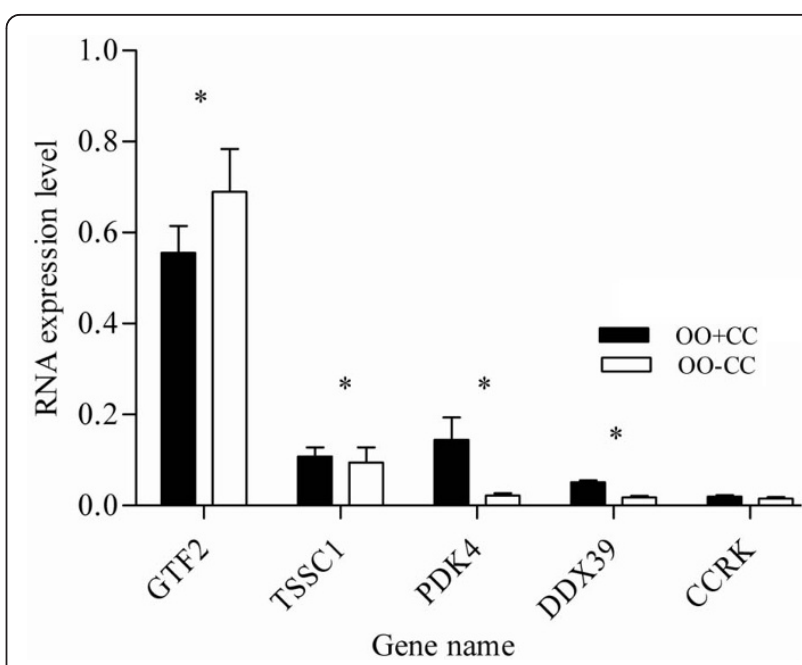

Figure 17 qRT-PCR validation of the array data showing some selected transcripts that are over expressed in oocytes cultured with their companion CCs compared with those cultured alone. Two bars representing the same gene and marked with $\operatorname{star}\left(^{*}\right)$ between them are significantly different $(P<0.05)$. $\mathrm{OO}+\mathrm{CC}=$ oocytes cultured with CCs and OO - CC $=$ oocytes cultured without CCs.

rearrangements, regulation of gene transcriptions, cell cycle regulation, control of apoptosis and membrane trafficking $[64,65]$. Phosphorylation and dephosphorylation of proteins are also crucial and control nearly every cellular activities, including metabolism, transcription and translation, cell-cycle progression, cytoskeletal

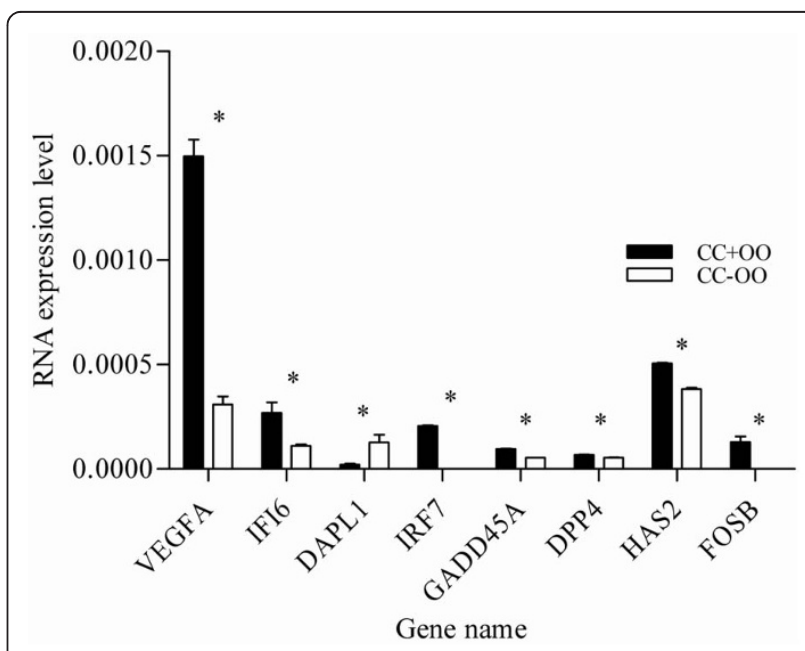

Figure 18 qRT-PCR validation of the array data showing some selected transcripts that are over expressed in CCs cultured with their enclosed oocytes compared with those cultured alone. Two bars representing the same gene and marked with star ${ }^{*} *$ between them are significantly different $(\mathrm{P}<0.05)$. $\mathrm{CC}+\mathrm{OO}=$ CCs cultured with their enclosed oocyte and CC - OO: CCs cultured without oocyte. 


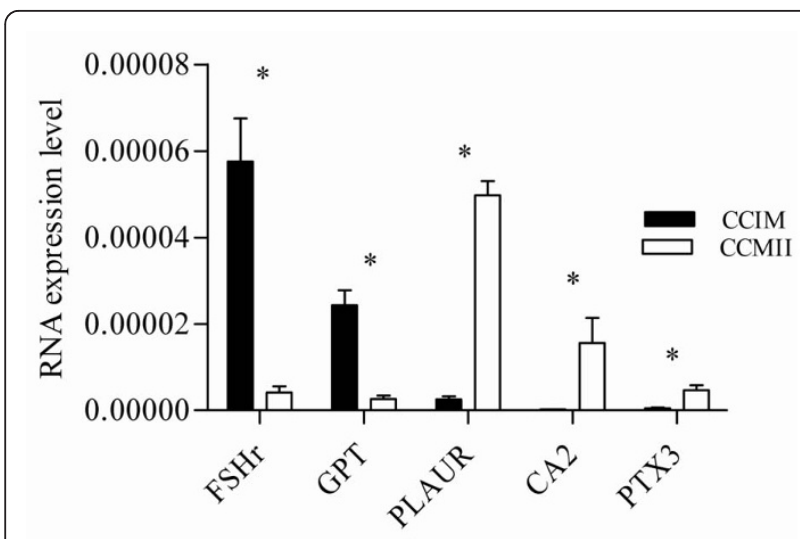

Gene name

Figure 19 qRT-PCR validation of the array data showing some selected transcripts that are differentially expressed between GV and MII CCs. Two bars representing the same gene and marked with star $\left(^{*}\right)$ between them are significantly different $(P<$ 0.05). CCIM = immature or GV stage CCS and CCMII = cultured or metaphase II CCs.

rearrangement, protein-protein interactions, protein stability, cell movement, and apoptosis. These processes in turn depend on the highly regulated and opposing actions of protein kinases (PKs) and phosphatases (PPs) where the balance between the two plays an important role in the control of oocyte meiotic resumption [66]. Consistent with this notion, we found oocyte specific expression of many of the members of trans-membrane proteins (TMEM30B, TMEM163, TMEM32, TMEM $120 B$ and TMEM52) and Rho GTPase activating proteins (ARHGAP10, 17, 18, 22, 24, 26, 27, 28), various members of the mitogene activated protein kinases (MAP4K2, MAPK10, MAPK8IP2), and phosphatases (PPP1R1B, PPP2R2B, PPP3R1, PPP1R3D) that may evidence the roles of these genes in meiotic maturation.

Like wise, some of the transcripts that were highly expressed in CCs relative to oocyte include IFIT5, BMP2, FSHr, GSTA1, FST, PTGR1, hormonal receptors and hormones such as INHA, INHBA, PGR and $P G R M C 2$. The oocyte and CC genes expression study has revealed that the receptor of $B M P 2$, also a receptor for $G D F 9$, is expressed only in CCs [42]. Similar studies have shown the expression of $B M P 2$ receptor in bovine antral follicles and its potential role in the development and functioning of ovarian follicles [21]. In support of these claims, we also detected this gene only in $\mathrm{CCs}$ suggesting its higher activity in CCs than in oocyte. GSTA1 is highly expressed in steroidogenically active cells of bovine ovarian follicle and suggested to intervene in folliculogenesis and oocyte maturation [67] and steroid receptor cells are found only in CCs evidencing the involvement of CCs derived GSTA1 in oocyte maturation. On the other hand, higher expression of

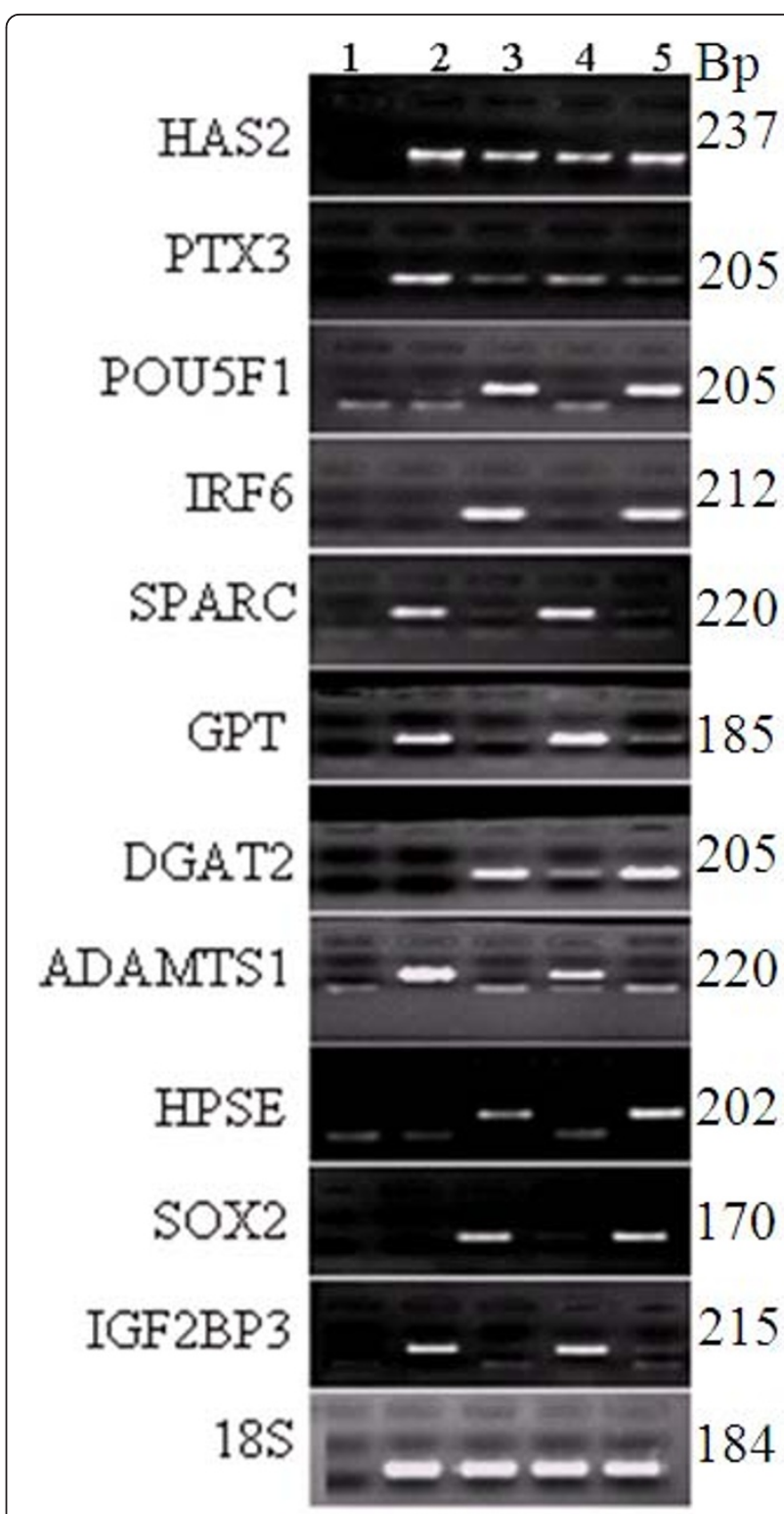

Figure 20 Validation of the microarray data by semi quantitative RT-PCR. A 2\% agarose gel electrophoresis depicting the mRNA expression of genes that are exclusively expressed either in oocytes or CCs. Number 1 shows a negative control (dd water as a template) and 2, 3, 4 and 5 show the abundance levels of each transcript in MII CCs, MII oocytes, GV CCs and GV oocytes, respectively. 185 was used as a loading control for total RNA.

FST and INHBA has been reported in cumulus oophorus that were obtained from in vivo produced COCs compared to these produced in vitro [68].

In order to validate the microarray data, specifically for those transcripts exclusively expressed in oocyte or CCs, we analyzed the expression of some selected genes using semi-quantitative PCR. A 2\% agarose gel pictures showing transcripts that are specific to oocyte or CCs 


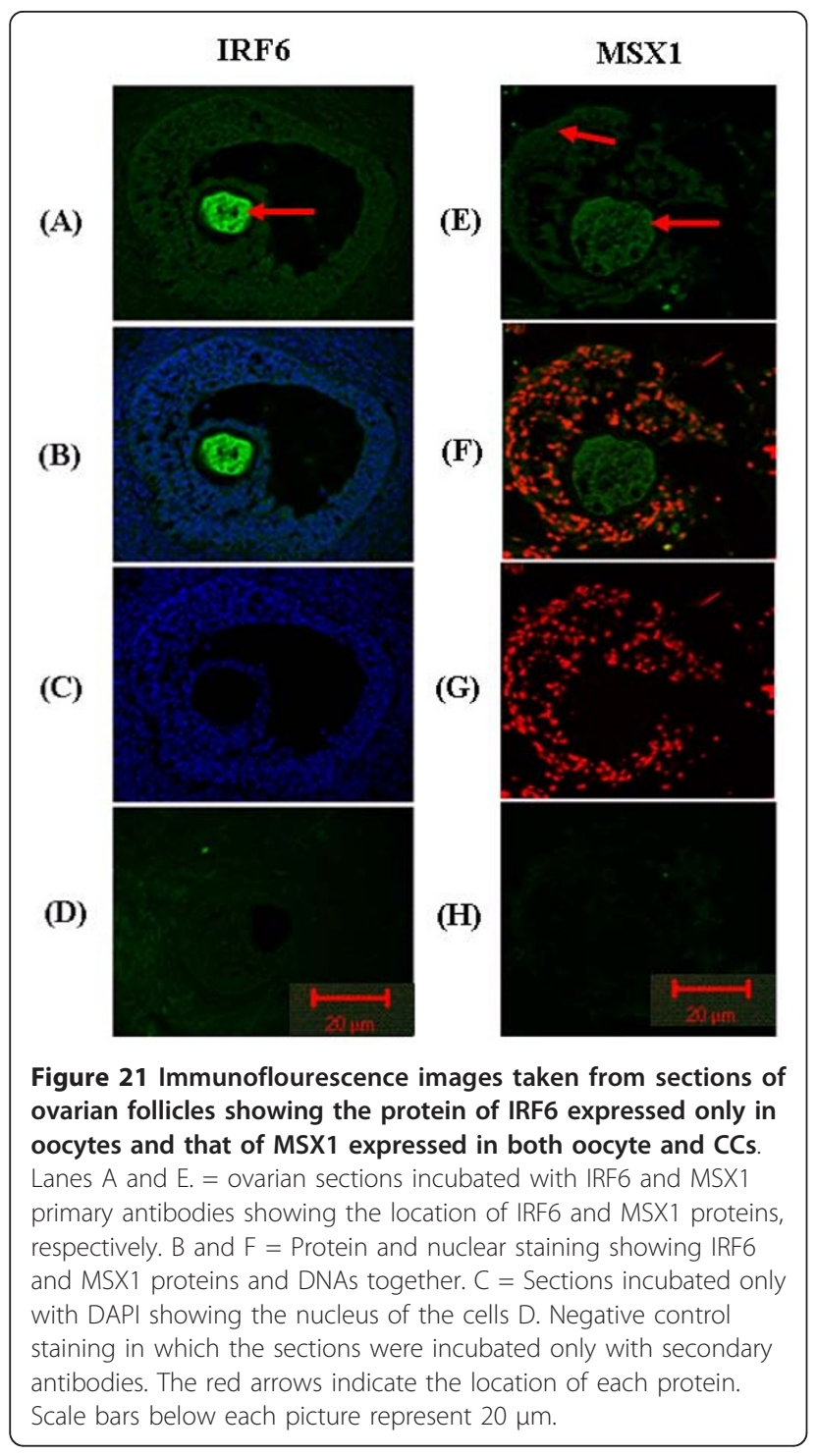

are shown in Figure 20. Previous studies have suggested that higher expression of HAS2, PTX3, TNFAIP6, PTGS2, CD44, INHBA and BTC in CCs can be used as molecular bio-markers to select quality embryo in women [40] and cow [48]. Higher expression of PTX3, PTGS2, ADAMTS1, INHA and INHBA was also reported in human CCs [42]. But, data that clearly demonstrate whether these transcripts are oocyte or CC specific or expressed in both is not available. Here, we show that none of HAS2, PTX3, INHA, INHBA and CD44 are CC specific as they are expressed in both samples (supplemental tables S3 and S6, Figure 20).

Additionally, we report for the first time that POU class 5 homeobox 1 (POU5F1), interferon regulatory factor 6 (IRF6), sex determining region Y box2 (SOX2) and insulin like growth factor 2 binding protein 3 (IGF2BP3) are expressed only in oocytes while secreted protein, acidic, cysteine-rich (SPARC), glutamate pyruvate transaminase (GPT), ADAM metallopeptidase with thrombospondin type 1 (ADAMTS1) and heparanase (HPSE) are expressed only in CCs. Significantly higher expression of POU5F1 has been reported in developmentally competent bovine oocytes and its loss of function has resulted in preimplantation lethality in mouse embryos as it is a central regulator of pluripotency [69]. Similarly, SOX2, which is expressed only in oocyte, is a developmental pluripotency marker and has been hypothesized as a regulator of POU5F1 controlled genes [70] suggesting a possible synergetic effect of the two genes on oocyte maturation.

IRF6 has been suggested as a key mediator of cellular proliferation and differentiation in mammary epithelial cells by facilitating entry into the G0 phase of the cell cycle [71]. It regulates cell proliferation and differentiation in different cell types and its higher expression in oocyte sample in the present study at both mRNA and protein levels (Figure 21) may show IRF6 as a maternal candidate transcript that play a role in acquiring developmental competence. ADAMTS1 is also expressed only in CCs but more abundantly at MII compared to at GV stage (Figure 20). Previously, increased expression of ADAMTS1 protein has been reported in mouse GCs in response to preovulatory LH surge [72] where it targets Versican $(V C A N)$, one of the proteins that cross link hyaluronic acid (HA) rich CCs matrix and contributes to oocyte maturation, ovulation and/or fertilization [73].

Transcripts specifically expressed in CCs also include SPARC, a multifunctional calcium-binding glycoprotein that modulates extracellular matrix interactions and influences cell-cell adhesion, migration and invasion in vitro and in vivo [74]. Although the role of SPARC in the biology of oocytes is not documented, the fact that it is expressed only CCs supports previous reports where it has been expressed only in the somatic cells of germarium and follicles during oogenesis [74].

The absence of CCs during in vitro maturation alters the gene expression profile of MII oocyte

Despite the fact that we did not observe significant morphological differences between oocyte matured with or without the surrounding cumulus cells including the polar body extrusion, previous study in bovine [38] has shown that oocytes matured without the surrounding cumulus cells resulted in significantly reduced blastocysts rates compared to those matured in the presence of the surrounding cumulus cells. Therefore, we hypothesized that the absence of cumulus cells during maturation can affect the nuclear and molecular maturation of the resulting oocytes. Maternal gene expression is an important biological process in oocyte maturation. If the oocyte is to complete normal 
maturation processes, the underlying transcriptional mechanism must be robust. Interestingly, some of the genes that are under expressed due to removal of CCs before in vitro maturation have vital roles in gene expression. The most important one is RNA polymerase II, an enzyme that plays a significant role in gene transcription. Reduced expression of this gene due to removal of $\mathrm{CCs}$ before in vitro maturation means the expression of other genes is greatly affected and hence the developmental competence of such oocytes is compromised.

In vitro studies have shown that follicle stimulating hormone (FSH) dependent cyclic adenosine monophosphate (cAMP), the activator of MAPK signaling, is produced by $\mathrm{CCs}$ and diffuses to the oocyte via the gap junction [75,76]. The activated MAPK in turn activates the components of MPF to initiate meiotic resumption [77] and simulate mos mRNA cytoplasmic polyadenylation during Xenopus [78,79] and mouse [80] oocyte maturation. Low expression of molecules that play roles in biochemistry of oocyte maturation (MAP3K2, MAP3K3 and MAP4K14) in OO-CCs samples may imply defects in the maturation process due to removal of CCs before maturation.

The capacity of the oocyte to metabolize glucose is positively correlated with its developmental potential and this depends on the presence of companion somatic cells $[81,82]$. Glucose is a pivotal metabolite for COCs and is metabolized via various pathways. During oocyte maturation, a large proportion of total glucose is metabolized in the CCs via the glycolytic pathway to provide substrates such as pyruvate for energy production [83]. Consistent with this, some genes that are involved in carbohydrate metabolism are under expressed due to removal of CCs indicating defective energy metabolism in the groups cultured without CCs and hence poor developmental competence.

In general, removal of companion CCs at GV stage appeared to affect the gene expression of MII oocytes as a number of genes are over expressed in oocytes cultured with CCs relative to those cultured without. As explained above, some of these genes have been implicated to be involved in various biological processes that are pertinent to oocyte meiotic resumption and maturation supporting the notion that the presence of CCs during in vitro maturation is crucial for oocyte developmental competence. However, the majority of these over expressed genes are uncharacterized and/or their functions, particularly with regard to oocyte development and maturation, are poorly understood. Paradoxically, several previously identified and biologically important OSFs (GDF9, BMP6, 15, TGFBs), zona pellucida proteins $(Z P 2,3,4)$, the components of MPF (CDK1 and Cyclin B1) and others are missing from the list of genes over expressed in $\mathrm{OO}+\mathrm{CCs}$.
From these results, it can be argued that either these over expressed genes have functional redundancy with those missing genes or the expression of the latter is completed prior to CCs removal at GV stage and consequently they are detected as equally as those cultured without their CCs. One plausible explanation inline of the latter argument is the fact that bovine oocytes are transcriptionally active during folliculogenesis and transcriptional activity decreases at later stages of follicular development [84]. Additionally, our present microarray data analysis between GV and MII oocytes (data not shown) reveals that only GDF9 and CDK1 are slightly over expressed (fold change $=2.46$ ) at MII relative to GV stage. Interestingly, while $B M P 15$ and TGFB2 are over expressed at GV stage, ZP2, 4 and Cyclin B1 are equally expressed between the two stages. Interestingly several genes have been found to be over expressed in MII stage relative to GV stage including $M P V 17$, ATP6V1D, TMEM127, NUDT14, UQCR, EXOSC6, MAPK10, CSNK1D, DBNL, FILIP1L, YIF1A and ARHGAP27. Considering the transcriptional activity of bovine oocytes, the over-expression of transcripts at MII stage compared to the GV stage need further investigation in terms of transcriptional regulation of genes during oocyte maturation.

\section{The absence of oocyte during in vitro maturation alters the gene expression profile of CCs}

Notable interspecies differences exist whether OSFs are mandatory for FSH induced CCs expansion in vitro. In rat, the presence of OSFs are crucial for in vitro CCs expansion as oocytectomized complexes ( $\mathrm{CCs}$ - OO) failed to expanded their cumulus oophorus [45]. In cattle and pig, CCs expansion doesn't depend on the presence of these factors as CCs - OO expanded as equally as the intact ones $[46,47]$. In the present study the results of IPA showed that some of the genes under expressed due to removal of oocyte before in vitro maturation are classified into cellular growth and proliferation (VEGFA, GADD45A, FOS, EGR1, HAS2), cell cycle (CCND2, CDCA8, CDK6), and gene expression (FOSB, TGFB2, ATF3) functional groups (Figure 9). These genes are also mapped into a complex gene network that includes genes involved in cellular development such as Cyclin D, HPSE, JUNB and others (Figure 9). Some of these genes are not well characterized and their direct role in the biology of CC is poorly understood. However, results of previous studies in different species have shown that some of these genes are involved in cumulus expansion and oocyte maturation. For instance, genes from FOS family have been implicated as regulators of cell proliferation, differentiation and transformation and IGFPB proteins stimulate the growth promoting effects of IGF1 which in turn is 
important for oocyte growth and maturation and granulosa cells proliferation [85].

Although a number of genes were differentially expressed between CCs that were cultured with or without their enclosed oocytes, it is not easy to conclude that removal of oocyte completely changes the expression of CCs genes at MII stage. For instance, except $H A S 2$, the majority of CCs genes previously identified as molecular bio markers for developmental competence including INH $\beta A$, EGFR, BTC, CD44, TNFAIP6, PTX3 and PTGS2 [40,48] were not differentially expressed between the two sample groups. From these results, we hypothesize that either these differentially expressed genes predict oocyte developmental competence better than the previously indentified ones or the transcription of these previously identified genes is completed earlier at GV stage before the ooplasm is removed and hence they are not differentially expression at MII stage. However, the assertion of both hypotheses requires further investigation.

\section{The dynamics of CCs transcriptome during the transition of COCs from GV to MII stages is associated with functional changes}

Massive transcript degradation during in vitro maturation of bovine [86], human [42,59] and mouse [59] oocytes has been reported. Similarly, considerable shift of transcripts and associated functional changes were observed in CCs during the transition of COCs from GV to MII stage. For instance, while transcripts that are involved in cell cycle, DNA replication, metabolic process, steroid and cholesterol biosynthesis, signal transduction and regulation of catalytic activity are over expressed in CCs at GV stage, these involved in cell adhesion, protein metabolic process, regulation of cellular component organization and biogenesis and actin filament polymerization are over expressed in CCs at MII stage (Figure 13). The most interesting finding of this experiment is not only the change in the number of transcripts but also the identity of transcripts that are involved in a given GO term at the two developmental stages.

Cell cycle and DNA replication are the two successive events which play significant roles in meiotic process resulting in the formation of four haploid cells. The functioning of a cell depends upon its ability to extract and use chemical energy stored in organic molecules via metabolic pathways. On the other hand, MAPK activation in CCs rather than in oocytes exerts essential functions during mammalian oocyte meiotic resumption $[66,87]$ and steroids such as progesterone have been suggested to induce cAMP dependent MAPK signaling cascade leading to meiotic resumption [88]. Hence, over expression of transcripts that are involved in cell cycle, metabolic and steroid biosynthetic pathways in CCs at GV stage suggest that these pathways are more active in GV than in MII stage.

As the oocyte lacks gonadotropin receptors, it has been hypothesized that FSH exerts its effect via a positive meiosis factor (EGF) synthesized by CCs indirectly via signal transduction pathway that involves cAMP dependent MAPK to induce meiotic resumption [89]. From these findings, we propose that over expression of transcripts that are involved in signal transduction pathway at GV stage CCs relative to MII is an indication that this pathway is more active at the former than the latter.

Focal adhesions are large macromolecular assemblies through which both mechanical force and regulatory signals are transmitted [90]. They serve not only to anchor the cell, but also to carry signals, which inform the cell about the condition of the ECM and thus affect their behaviour [91]. In view of their increased expression at MII relative to their expression at GV stage, we propose that these genes are involved in one of the regulatory network that connects the oocyte to its companion CCs during in vitro maturation.

Actin filaments localize to specific regions within mammalian oocytes and their modelling including polymerization are important for oocyte maturation, fertilization and embryo development [76,92,93]. Interestingly, we found higher expression of transcripts that are involved in actin filament polymerization at MII than in GV CCs. Consistent with the notion that in vitro meiotic resumption in bovine oocytes is triggered by FSH $[76,93]$; we observed higher expression of FSHR mRNA in GV CCs than in MII stage. Prior to in vitro meiotic resumption, FSH is received by CGCs via FSHR and this activates the release of $\mathrm{CAMP}$ and MAPK signaling pathways to initiate meiotic resumption [88].

CCs expansion is a key biological event for successful oocyte maturation, ovulation and fertility $[40,48,94,95]$. HAS2 is an important enzyme for the biosynthesis of HA to form stable matrix during CCs expansion [96]. The binding proteins of HA (TNFAIP6 and PTX3) and its receptor protein $(C D 44)$ plays significant roles in attaining full CC expansion. CD44 is a widely expressed cell adhesion molecule that binds the extracellular matrix component, HA in a tightly regulated manner [97]. The interaction between HA and CD44 is the key molecular mechanism for the activation of signalling cascades that contribute to cell adhesion, proliferation, migration and differentiation $[98,99]$. This interaction is also important for MAPK signalling pathway in oocyte and may promote meiotic resumption [100]. Oocytes can't attain cytoplasmic maturation when cultured in the absence of their companion CCs as they can't store sufficient mRNAs, proteins and transcription factors that are important for maturation 
process due to removal of the b-idirectional communication axis. The interaction between $H A-C D 44$ is critical for modification of this communication axis during CCs expansion [101] and relatively higher expression of these molecules in cultured CCs is consistent with the notion that $H A-C D 44$ interactive effect is vital for oocyte maturation [100].

The majority of genes differentially expressed between different oocyte and CCs samples are poorly characterized and their roles in the biology of bovine oocyte are not known. Moreover, due to the dynamic nature of gene expression in different species, tissues and follicular stages, what have been reported so far in other organisms may not necessarily hold true for bovine oocytes and CCs. Therefore, we recommend detailed gene by gene study to unveil specific roles of these genes in the biology of bovine COCs.

\section{Conclusion}

In conclusion, this study has generated large scale gene expression data from different oocyte and CCs samples that would provide insights into gene functions and interactions within and across different pathways that are involved in the maturation of bovine oocytes. Moreover, the presence or absence of oocyte and CC factors during bovine oocyte maturation can have a profound effect on transcript abundance in each cell types, showing the molecular cross-talk between oocytes and their corresponding CCs.

\section{Additional material}

Additional file 1: The Six MIAME guidelines that were adopted to conduct the study.

Additional file 2: List of transcripts that are exclusively expressed in GV oocytes relative to GV CCs.

Additional file 3: List of transcripts that are exclusively expressed in GV CCs relative to GV oocytes.

Additional file 4: List of transcripts that are expressed in both GV oocytes and CCs.

Additional file 5: List of transcripts that are expressed only MII CCS.

Additional file 6: List of transcripts that are expressed in both MII oocytes and CCs.

Additional file 7: List of transcripts that are differentially expressed between GV oocytes and CCs.

Additional file 8: List of transcripts that are expressed only in MII oocytes.

Additional file 9: List of transcripts that are differentially expressed between MII oocytes and CCs.

Additional file 10: The top significantly changed GO (molecular functions) with the proportion of transcripts that are over expressed in GV oocytes and CCs $(P<0.001)$.

Additional file 11: The top significantly changed GO (molecular functions) with the proportion of transcripts that are over expressed in MII oocytes and CCs $(P<0.001)$.
Additional file 12: List of transcripts that are differentially expressed between oocytes cultured with or without their companion CCs

Additional file 13: List of transcripts that are differentially expressed between CCs cultured with or without their oocyte. Additional file 14: The seven most prominent canonical pathways involving genes that are over expressed in $\mathrm{OO}+\mathrm{CCs}$ relative to OO - CCs with P-values, $\mathbf{0 . 0 5}$. The bars represent the P-value for each pathway. The orange irregular line is a graph of the ratio (genes from the data set/total number of genes involved in the pathway) for the different pathways.

Additional file 15: The five most prominent canonical pathways involving genes that are over expressed in $\mathrm{CCs}+\mathrm{OO}$ relative to CCs - OO with P-values, $\mathbf{0 . 0 5}$. The bars represent the P-value for each pathway. The orange irregular line is a graph of the ratio (genes from the data set/total number of genes involved in the pathway) for the different pathways.

Additional file 16: List of transcripts that are exclusively expressed in GV CCs compared to MII CCs.

Additional file 17: List of transcripts that are exclusively expressed in MII CCs compared with GV CCs.

Additional file 18: List of transcripts that are commonly expressed between CCs at GV and MII stages.

Additional file 19: List of transcripts that are differentially expressed between GV and MII CCs.

Additional file 20: qRT-PCR validation of the microarray data showing the change in the expression levels of transcripts differentially expressed between GV oocytes and CCs. Transcripts marked by the minus sign indicate those over expressed in GV CCs.

Additional file 21: qRT-PCR validation of the microarray data showing the change in the expression levels of transcripts differentially expressed between MII oocytes and CCs. Transcripts marked by the minus sign indicate those over expressed in MII CCs.

Additional file 22: qRT-PCR validation of the microarray data showing the change in the expression levels of transcripts differentially expressed between oocytes cultured with their companion CCs relative to those cultured alone. Transcripts marked by the minus sign indicate those over expressed in oocytes cultured without their companion CCS.

Additional file 23: qRT-PCR validation of the microarray data showing the change in the expression levels of transcripts differentially expressed between CCs cultured with their enclosed oocytes relative to those cultured alone. Transcripts marked by the minus sign indicate those over expressed in CCs cultured without their enclosed oocytes.

Additional file 24: qRT-PCR validation of the microarray data showing the change in the expression levels of transcripts differentially expressed between CCs at germinal vesicle (GV) and metaphase II (MII) stages. Transcripts marked by the minus sign indicate those over expressed in MII stage relative to GV stage.

\section{Acknowledgements}

We would like to acknowledge the Institute of Life and Brain, University of Bonn, for allowing us to use their laboratory facilities for Affymetrix GenChip hybridization. Our special thanks are due to Ms. Astrid Becker for her kind assistance during microarray hybridization.

\section{Authors' contributions}

AR developed the project, carried out the experiment, analysed the data, prepared the drafting of the manuscript and corrected it after revision. FR and $\mathrm{MH}$ prepared oocyte and CCs samples for molecular analysis. UC, ET and $C L$ were involved in the discussion of the experimental design and during follow-up of the experiment. KS supervised the work and provided 
suggestion. DT developed the project and reviewed the manuscript. Al authors read and approved the final manuscript.

Received: 26 March 2010 Accepted: 24 January 2011

Published: 24 January 2011

\section{References}

1. Eppig JJ: Oocyte control of ovarian follicular development and function in mammals. Reproduction 2001, 122(6):829-838.

2. Gilchrist RB, Ritter LJ, Armstrong DT: Oocyte-somatic cell interactions during follicle development in mammals. Anim Reprod Sci 2004, 82-83:431-446.

3. Matzuk MM, Burns KH, Viveiros MM, Eppig JJ: Intercellular communication in the mammalian ovary, oocytes carry the conversation. Science 2002, 296(5576):2178-2180.

4. Brower PT, Schultz RM: Intercellular communication between granulosa cells and mouse oocytes, existence and possible nutritional role during oocyte growth. Dev Biol 1982, 90(1):144-153.

5. Calder MD, Caveney AN, Sirard MA, Watson AJ: Effect of serum and cumulus cell expansion on marker gene transcripts in bovine cumulusoocyte complexes during maturation in vitro. Fertil Steril 2005, 83(1):1077-1085.

6. Calder MD, Caveney AN, Westhusin ME, Watson AJ: Cyclooxygenase-2 and prostaglandin $\mathrm{E}(2)(\mathrm{PGE}(2))$ receptor messenger RNAs are affected by bovine oocyte maturation time and cumulus-oocyte complex quality, and PGE(2) induces moderate expansion of the bovine cumulus in vitro. Biol Reprod 2001, 65(1):135-140.

7. De La Fuente R, Eppig JJ: Transcriptional activity of the mouse oocyte genome: companion granulosa cells modulate transcription and chromatin remodeling. Dev Biol 2001, 229(1):224-236.

8. Eppig JJ: Intercommunication between mammalian oocytes and companion somatic cells. Bioessays 1991, 13(11):569-574

9. Eppig JJ, Wigglesworth K, Pendola FL: The mammalian oocyte orchestrates the rate of ovarian follicular development. Proc Natl Acad Sci USA 2002, 99(5):2890-2894.

10. Gilchrist RB, Morrissey MP, Ritter $L$, Armstrong DT: Comparison of oocyte factors and transforming growth factor-beta in the regulation of DNA synthesis in bovine granulosa cells. Mol Cell Endocrinol 2003, 201(1-2):87-95.

11. Gilchrist RB, Ritter $L$, Armstrong DT: Mouse oocyte mitogenic activity is developmentally coordinated throughout folliculogenesis and meiotic maturation. Dev Biol 2001, 240(1):289-298

12. Gilchrist RB, Ritter LJ, Myllymaa S, Kaivo-Oja N, Dragovic RA, Hickey TE, Ritvos O, Mottershead DG: Molecular basis of oocyte-paracrine signalling that promotes granulosa cell proliferation. J Cell Sci 2006, 119(18):3811-3821

13. Li R, Norman RJ, Armstrong DT, Gilchrist RB: Oocyte-secreted factor(s) determine functional differences between bovine mural granulosa cells and cumulus cells. Biol Reprod 2000, 63(3):839-845.

14. Hussein TS, Froiland DA, Amato F, Thompson JG, Gilchrist RB: Oocytes prevent cumulus cell apoptosis by maintaining a morphogenic paracrine gradient of bone morphogenetic proteins. J Cell Sci 2005 118(22):5257-5268

15. Eppig JJ, Wigglesworth K, Pendola F, Hirao Y: Murine oocytes suppress expression of luteinizing hormone receptor messenger ribonucleic acid by granulosa cells. Biol Reprod 1997, 56(4):976-984.

16. Eppig JJ, Pendola FL, Wigglesworth K, Pendola JK: Mouse oocytes regulate metabolic cooperativity between granulosa cells and oocytes, amino acid transport. Biol Reprod 2005, 73(2):351-357.

17. Buccione R, Vanderhyden BC, Caron PJ, Eppig JJ: FSH-induced expansion of the mouse cumulus oophorus in vitro is dependent upon a specific factor(s) secreted by the oocyte. Dev Biol 1990, 138(1):16-25.

18. Vanderhyden BC, Caron PJ, Buccione R, Eppig JJ: Developmental pattern of the secretion of cumulus expansion-enabling factor by mouse oocytes and the role of oocytes in promoting granulosa cell differentiation. Dev Biol 1990, 140(2):307-317.

19. Lucidi P, Bernabo N, Turriani M, Barboni B, Mattioli M: Cumulus cells steroidogenesis is influenced by the degree of oocyte maturation. Reprod Biol Endocrinol 2003, 1:45.

20. Sutton-McDowall ML, Gilchrist RB, Thompson JG: Cumulus expansion and glucose utilisation by bovine cumulus-oocyte complexes during in vitro maturation, the influence of glucosamine and follicle-stimulating hormone. Reproduction 2004, 128(3):313-319.

21. Fatehi AN, Roelen BA, Colenbrander B, Schoevers EJ, Gadella BM, Beverst MM, van den Hurk R: Presence of cumulus cells during in vitro fertilization protects the bovine oocyte against oxidative stress and improves first cleavage but does not affect further development. Zygote 2005, 13(2):177-185.

22. Tatemoto H, Sakurai N, Muto N: Protection of porcine oocytes against apoptotic cell death caused by oxidative stress during In vitro: maturation role of cumulus cells. Biol Reprod 2000, 63(3):805-810.

23. de Matos DG, Furnus CC, Moses DF: Glutathione synthesis during in vitro maturation of bovine oocytes, role of cumulus cells. Biol Reprod 1997, 57(6):1420-1425.

24. de Matos DG, Gasparrini B, Pasqualini SR, Thompson JG: Effect of glutathione synthesis stimulation during in vitro maturation of ovine oocytes on embryo development and intracellular peroxide content. Theriogenology 2002, 57(5):1443-1451.

25. Fukui Y: Effect of follicle cells on the acrosome reaction, fertilization, and developmental competence of bovine oocytes cultured in vitro. $\mathrm{Mol}$ Reprod Dev 1990, 26(1):40-46.

26. Moor RM, Mattioli M, Ding J, Nagai T: Maturation of pig oocytes in vivo and in vitro. J Reprod Fertil Supp/ 1990, 40:197-210.

27. Vanderhyden BC, Armstrong DT: Role of cumulus cells and serum on the in vitro maturation, fertilization, and subsequent development of rat oocytes. Biol Reprod 1989, 40(4):720-728.

28. Suzuki K, Eriksson B, Shimizu H, Nagai T, Rodriguez-Martinez H: Effect of hyaluronan on monospermic penetration of porcine oocytes fertilized in vitro. Int J Androl 2000, 23(1):13-21.

29. Tajik P, Niwa K, Murase T: Effects of different protein supplements in fertilization medium on in vitro penetration of cumulus-intact and cumulus-free bovine oocytes cultured in culture. Theriogenology 1993, 40(5):949-958

30. Zhang L, Jiang S, Wozniak PJ, Yang X, Godke RA: Cumulus cell function during bovine oocyte maturation, fertilization, and embryo development in vitro. Mol Reprod Dev 1995, 40(3):338-344

31. Eppig JJ, Wigglesworth $K$, Chesnel F: Secretion of cumulus expansion enabling factor by mouse oocytes: relationship to oocyte growth and competence to resume meiosis. Dev Biol 1993, 158(2):400-409.

32. Tanghe S, Van Soom A, Nauwynck H, Coryn M, de Kruif A: Minireview: Functions of the cumulus oophorus during oocyte maturation, ovulation, and fertilization. Mol Reprod Dev 2002, 61(3):414-424.

33. Joyce IM, Clark AT, Pendola FL, Eppig JJ: Comparison of recombinant growth differentiation factor-9 and oocyte regulation of KIT ligand messenger ribonucleic acid expression in mouse ovarian follicles. Biol Reprod 2000, 63(6):1669-1675.

34. Otsuka F, Shimasaki S: A negative feedback system between oocyte bone morphogenetic protein 15 and granulosa cell kit ligand: its role in regulating granulosa cell mitosis. Proc Natl Acad Sci USA 2002, 99(12):8060-8065.

35. Herlands RL, Schultz RM: Regulation of mouse oocyte growth: probable nutritional role for intercellular communication between follicle cells and oocytes in oocyte growth. J Exp Zool 1984, 229(2):317-325.

36. Hashimoto S, Saeki K, Nagao Y, Minami N, Yamada M, Utsumi K: Effects of cumulus cell density during in vitro maturation of the developmental competence of bovine oocytes. Theriogenology 1998, 49(8):1451-1463.

37. Vozzi C, Formenton A, Chanson A, Senn A, Sahli R, Shaw P, Nicod P, Germond M, Haefliger JA: Involvement of connexin 43 in meiotic maturation of bovine oocytes. Reproduction 2001, 122(4):619-628.

38. Atef A, Francois P, Christian V, Marc-Andre S: The potential role of gap junction communication between cumulus cells and bovine oocytes during in vitro maturation. Mol Reprod Dev 2005, 71(3):358-367.

39. Gregory L: Ovarian markers of implantation potential in assisted reproduction. Hum Reprod 1998, 13(4):117-132.

40. McKenzie LJ, Pangas SA, Carson SA, Kovanci E, Cisneros P, Buster JE, Amato $P$, Matzuk MM: Human cumulus granulosa cell gene expression: a predictor of fertilization and embryo selection in women undergoing IVF. Hum Reprod 2004, 19(12):2869-2874

41. Hizaki H, Segi E, Sugimoto $Y$, Hirose M, Saji T, Ushikubi F, Matsuoka T, Noda Y, Tanaka T, Yoshida N, et al: Abortive expansion of the cumulus and impaired fertility in mice lacking the prostaglandin $E$ receptor subtype EP(2). Proc Natl Acad Sci USA 1999, 96(18):10501-10506. 
42. Assou S, Anahory T, Pantesco V, Le Carrour T, Pellestor F, Klein B, Reyftmann L, Dechaud H, De Vos J, Hamamah S: The human cumulusoocyte complex gene-expression profile. Hum Reprod 2006, 21(7):1705-1719.

43. Assou S, Haouzi D, De Vos J, Hamamah S: Human cumulus cells as biomarkers for embryo and pregnancy outcomes. Mol Hum Reprod 2010, 16(8):531-538.

44. Hamel M, Dufort I, Robert C, Leveille MC, Leader A, Sirard MA: Identification of follicular marker genes as pregnancy predictors for human IVF: new evidence for the involvement of luteinization process. Mol Hum Reprod 2008, 16(8):548-556.

45. Vanderhyden BC: Species differences in the regulation of cumulus expansion by an oocyte-secreted factor(s). J Reprod Fertil 1993, 98(1):219-227.

46. Ralph JH, Telfer EE, Wilmut I: Bovine cumulus cell expansion does not depend on the presence of an oocyte secreted factor. Mol Reprod Dev 1995, 42(2):248-253.

47. Prochazka R, Nagyova E, Rimkevicova Z, Nagai T, Kikuchi K, Motlik J: Lack of effect of oocytectomy on expansion of the porcine cumulus. J Reprod Fertil 1991, 93(2):569-576.

48. Assidi M, Dufort I, Ali A, Hamel M, Algriany O, Dielemann S, Sirard MA: Identification of potential markers of oocyte competence expressed in bovine cumulus cells cultured with follicle-stimulating hormone and/or phorbol myristate acetate in vitro. Biol Reprod 2008, 79(2):209-222.

49. Bettegowda A, Patel OV, Lee KB, Park KE, Salem M, Yao J, Ireland JJ, Smith GW: Identification of novel bovine cumulus cell molecular markers predictive of oocyte competence: functional and diagnostic implications. Biol Reprod 2008, 79(2):301-309.

50. Pujol M, Lopez-Bejar M, Paramio MT: Developmental competence of heifer oocytes selected using the brilliant cresyl blue (BCB) test. Theriogenology 2004, 61(4):735-744.

51. Rodriguez-Gonzalez E, Lopez-Bejar M, Izquierdo D, Paramio MT: Developmental competence of prepubertal goat oocytes selected with brilliant cresyl blue and cultured with cysteamine supplementation. Reprod Nutr Dev 2003, 43(2):179-187.

52. Torner $\mathrm{H}$, Ghanem $\mathrm{N}$, Ambros C, Holker M, Tomek W, Phatsara C, Alm H, Sirard MA, Kanitz W, Schellander K, et al: Molecular and subcellular characterisation of oocytes screened for their developmental competence based on glucose-6-phosphate dehydrogenase activity. Reproduction 2008, 135(2):197-212.

53. Memili E, Peddinti D, Shack LA, Nanduri B, McCarthy F, Sagirkaya H, Burgess SC: Bovine germinal vesicle oocyte and cumulus cell proteomics. Reproduction 2007, 133(6):1107-1120.

54. Irizarry RA, Bolstad BM, Collin F, Cope LM, Hobbs B, Speed TP: Summaries of Affymetrix GeneChip probe level data. Nucleic Acids Res 2003, 31(4):e15.

55. Mah N, Thelin A, Lu T, Nikolaus S, Kuhbacher T, Gurbuz Y, Eickhoff H, Kloppel G, Lehrach H, Mellgard B, et al: A comparison of oligonucleotide and cDNA-based microarray systems. Physiol Genomics 2004, 16(3):361-370

56. Smyth GK: Linear models and empirical bayes methods for assessing differential expression in microarray experiments. Stat Appl Genet Mol Biol 2004, 3, Article3.

57. Ashburner M, Ball CA, Blake JA, Botstein D, Butler H, Cherry JM, Davis AP, Dolinski K, Dwight SS, Eppig JT, et al: Gene ontology: tool for the unification of biology. The Gene Ontology Consortium. Nat Genet 2000, 25(1):25-29

58. Whelan JA, Russell NB, Whelan MA: A method for the absolute quantification of cDNA using real-time PCR. J Immunol Methods 2003, 278(1-2):261-269.

59. Su YQ, Sugiura K, Woo Y, Wigglesworth K, Kamdar S, Affourtit J, Eppig JJ: Selective degradation of transcripts during meiotic maturation of mouse oocytes. Dev Biol 2007, 302(1):104-117.

60. Hussein TS, Thompson JG, Gilchrist RB: Oocyte-secreted factors enhance oocyte developmental competence. Dev Biol 2006, 296(2):514-521.

61. McNatty KP, Moore LG, Hudson NL, Quirke LD, Lawrence SB, Reader K, Hanrahan JP, Smith P, Groome NP, Laitinen M, et al: The oocyte and its role in regulating ovulation rate: a new paradigm in reproductive biology. Reproduction 2004, 128(4):379-386.

62. Yew N, Mellini ML, Vande Woude GF: Meiotic initiation by the mos protein in Xenopus. Nature 1992, 355(6361):649-652.

63. Hunt T: Cell cycle arrest and c-mos. Nature 1992, 355(6361):587-588.
64. Bishop AL, Hall A: Rho GTPases and their effector proteins. Biochem J 2000, 348(2):241-255.

65. Hall A: Rho GTPases and the actin cytoskeleton. Science 1998, 279(5350):509-514

66. Liang CG, Su YQ, Fan HY, Schatten $H$, Sun QY: Mechanisms regulating oocyte meiotic resumption: roles of mitogen-activated protein kinase. Mol Endocrinol 2007, 21(9):2037-2055.

67. Rabahi F, Brule S, Sirois J, Beckers JF, Silversides DW, Lussier JG: High expression of bovine alpha glutathione S-transferase (GSTA1, GSTA2) subunits is mainly associated with steroidogenically active cells and regulated by gonadotropins in bovine ovarian follicles. Endocrinology 1999, 140(8):3507-3517.

68. Tesfaye D, Ghanem N, Carter F, Fair T, Sirard MA, Hoelker M, Schellander K, Lonergan P: Gene expression profile of cumulus cells derived from cumulus-oocyte complexes cultured either in vivo or in vitro. Reprod Fertil Dev 2009, 21(3):451-461.

69. Nichols J, Zevnik B, Anastassiadis K, Niwa H, Klewe-Nebenius D, Chambers I, Scholer $\mathrm{H}$, Smith A: Formation of pluripotent stem cells in the mammalian embryo depends on the POU transcription factor Oct4. Cell 1998, 95(3):379-391.

70. Botquin V, Hess H, Fuhrmann G, Anastassiadis C, Gross MK, Vriend G, Scholer HR: New POU dimer configuration mediates antagonistic control of an osteopontin preimplantation enhancer by Oct-4 and Sox-2. Genes Dev 1998, 12(13):2073-2090.

71. Bailey CM, Abbott DE, Margaryan NV, Khalkhali-Ellis Z, Hendrix MJ: Interferon regulatory factor 6 promotes cell cycle arrest and is regulated by the proteasome in a cell cycle-dependent manner. Mol Cell Biol 2008, 28(7):2235-2243

72. Russell DL, Doyle KM, Ochsner SA, Sandy JD, Richards JS: Processing and localization of ADAMTS-1 and proteolytic cleavage of versican during cumulus matrix expansion and ovulation. J Biol Chem 2003, 278(43):42330-42339

73. Dunning KR, Lane M, Brown HM, Yeo C, Robker RL, Russell DL: Altered composition of the cumulus-oocyte complex matrix during in vitro maturation of oocytes. Hum Reprod 2007, 22(11):2842-2850.

74. Martinek N, Shahab J, Saathoff M, Ringuette M: Haemocyte-derived SPARC is required for collagen-IV-dependent stability of basal laminae in Drosophila embryos. J Cell Sci 2008, 121(10):1671-1680.

75. Thomas RE, Armstrong DT, Gilchrist RB: Bovine cumulus cell-oocyte gap junctional communication during in vitro maturation in response to manipulation of cell-specific cyclic adenosine 3',5'-monophosophate levels. Biol Reprod 2004, 70(3):548-556.

76. Webb RJ, Marshall F, Swann K, Carroll J: Follicle-stimulating hormone induces a gap junction-dependent dynamic change in [CAMP] and protein kinase a in mammalian oocytes. Dev Biol 2002, 246(2):441-454

77. Tremblay K, Vigneault C, McGraw S, Sirard MA: Expression of cyclin B1 messenger RNA isoforms and initiation of cytoplasmic polyadenylation in the bovine oocyte. Biol Reprod 2005, 72(4):1037-1044.

78. Howard EL, Charlesworth A, Welk J, MacNicol AM: The mitogen-activated protein kinase signaling pathway stimulates mos mRNA cytoplasmic polyadenylation during Xenopus oocyte maturation. Mol Cell Biol 1999, 19(3):1990-1999.

79. Zhang $Y$, Sheets MD: Analyses of zebrafish and Xenopus oocyte maturation reveal conserved and diverged features of translational regulation of maternal cyclin B1 mRNA. BMC Dev Biol 2009, 9:7.

80. Gebauer F, Xu W, Cooper GM, Richter JD: Translational control by cytoplasmic polyadenylation of c-mos mRNA is necessary for oocyte maturation in the mouse. EMBO J 1994, 13(23):5712-5720.

81. Rieger D, Loskutoff NM: Changes in the metabolism of glucose, pyruvate, glutamine and glycine during maturation of cattle oocytes in vitro. J Reprod Fertil 1994, 100(1):257-262.

82. Saito $T$, Hiroi M, Kato $T$ : Development of glucose utilization studied in single oocytes and preimplantation embryos from mice. Biol Reprod 1994, 50(2):266-270.

83. Sutton-McDowall ML, Gilchrist RB, Thompson JG: The pivotal role of glucose metabolism in determining oocyte developmental competence. Reproduction 139(4):685-695.

84. Memili E, First NL: Developmental changes in RNA polymerase II in bovine oocytes, early embryos, and effect of alpha-amanitin on embryo development. Mol Reprod Dev 1998, 51(4):381-389. 
85. Zhou J, Chin E, Bondy C: Cellular pattern of insulin-like growth factor-I (IGF-I) and IGF-I receptor gene expression in the developing and mature ovarian follicle. Endocrinology 1991, 129(6):3281-3288.

86. Fair T, Hyttel P, Greve T: Bovine oocyte diameter in relation to maturational competence and transcriptional activity. Mol Reprod Dev 1995, 42(4):437-442.

87. Liang CG, Huo LJ, Zhong ZS, Chen DY, Schatten H, Sun QY: Cyclic adenosine 3',5'-monophosphate-dependent activation of mitogenactivated protein kinase in cumulus cells is essential for germinal vesicle breakdown of porcine cumulus-enclosed oocytes. Endocrinology 2005, 146(10):4437-4444.

88. Shimada M, Terada T: FSH and LH induce progesterone production and progesterone receptor synthesis in cumulus cells: a requirement for meiotic resumption in porcine oocytes. Mol Hum Reprod 2002, 8(7):612-618.

89. Downs SM, Daniel SA, Eppig JJ: Induction of maturation in cumulus cellenclosed mouse oocytes by follicle-stimulating hormone and epidermal growth factor: evidence for a positive stimulus of somatic cell origin. J Exp Zool 1988, 245(1):86-96.

90. Chen CS, Alonso JL, Ostuni E, Whitesides GM, Ingber DE: Cell shape provides global control of focal adhesion assembly. Biochem Biophys Res Commun 2003, 307(2):355-361.

91. Riveline D, Zamir E, Balaban NQ, Schwarz US, Ishizaki T, Narumiya S, Kam Z, Geiger B, Bershadsky AD: Focal contacts as mechanosensors: externally applied local mechanical force induces growth of focal contacts by an mDia1-dependent and ROCK-independent mechanism. J Cell Biol 2001, 153(6):1175-1186.

92. Rawe VY, Payne C, Schatten G: Profilin and actin-related proteins regulate microfilament dynamics during early mammalian embryogenesis. Hum Reprod 2006, 21(5):1143-1153.

93. van Tol HT, van Eijk MJ, Mummery $\mathrm{CL}$, van den Hurk R, Bevers MM: Influence of FSH and hCG on the resumption of meiosis of bovine oocytes surrounded by cumulus cells connected to membrana granulosa. Mol Reprod Dev 1996, 45(2):218-224.

94. Kimura N, Konno Y, Miyoshi K, Matsumoto H, Sato E: Expression of hyaluronan synthases and CD44 messenger RNAs in porcine cumulusoocyte complexes during in vitro maturation. Biol Reprod 2002, 66(3):707-717.

95. Ochsner SA, Day AJ, Rugg MS, Breyer RM, Gomer RH, Richards JS: Disrupted function of tumor necrosis factor-alpha-stimulated gene 6 blocks cumulus cell-oocyte complex expansion. Endocrinology 2003, 144(10):4376-4384.

96. Simpson MA, Wilson CM, Furcht LT, Spicer AP, Oegema TR Jr, McCarthy JB: Manipulation of hyaluronan synthase expression in prostate adenocarcinoma cells alters pericellular matrix retention and adhesion to bone marrow endothelial cells. J Biol Chem 2002, 277(12):10050-10057.

97. Lesley J, Hyman R, Kincade PW: CD44 and its interaction with extracellular matrix. Adv Immunol 1993, 54:271-335.

98. Bourguignon LY: CD44-mediated oncogenic signaling and cytoskeleton activation during mammary tumor progression. J Mammary Gland Biol Neoplasia 2001, 6(3):287-297.

99. Turley EA, Noble PW, Bourguignon LY: Signaling properties of hyaluronan receptors. J Biol Chem 2002, 277(7):4589-4592.

100. Kimura N, Hoshino Y, Totsukawa K, Sato E: Cellular and molecular events during oocyte maturation in mammals: molecules of cumulus-oocyte complex matrix and signalling pathways regulating meiotic progression. Soc Reprod Fertil Suppl 2007, 63:327-342.

101. Yokoo M, Sato E: Cumulus-oocyte complex interactions during oocyte maturation. Int Rev Cytol 2004, 235:251-291.

doi:10.1186/1471-2164-12-57

Cite this article as: Regassa et al:: Transcriptome dynamics and molecular cross-talk between bovine oocyte and its companion cumulus cells. BMC Genomics 2011 12:57.

\section{Submit your next manuscript to BioMed Central and take full advantage of:}

- Convenient online submission

- Thorough peer review

- No space constraints or color figure charges

- Immediate publication on acceptance

- Inclusion in PubMed, CAS, Scopus and Google Scholar

- Research which is freely available for redistribution

Submit your manuscript at www.biomedcentral.com/submit
C Biomed Central 